TITLE:

\title{
Measurements of liquid film and droplets of annular two-phase flow on a rod-bundle geometry with spacer
}

\section{$\operatorname{AUTHOR}(S):$}

Pham, Son H.; Kawara, Zensaku; Yokomine, Takehiko; Kunugi, Tomoaki

\section{CITATION:}

Pham, Son H.... [et al]. Measurements of liquid film and droplets of annular two-phase flow on a rod-bundle geometry with spacer. International Journal of Multiphase Flow 2015, 70: 35-57

ISSUE DATE:

2015-04

URL:

http://hdl.handle.net/2433/193247

\section{RIGHT:}

@ 2014 Elsevier Ltd.; この論文は出版社版でありません。引用の際には 出版社版をご確認ご利用ください。; This is not the published version. Please cite only the published version. 


\title{
Measurements of liquid film and droplets of annular two-phase flow on a rod-bundle geometry with spacer
}

$8 \quad$ aphamhsv@gmail.com

9 bkawara@nucleng.kyoto-u.ac.jp

\section{cyokomine@nucleng.kyoto-u.ac.jp}

’unugi@nucleng.kyoto-u.ac.jp

\author{
Son H. Phamª, Zensaku Kawarab ${ }^{\mathrm{b}}$, Takehiko Yokominec, Tomoaki Kunugid,* \\ Department of Nuclear Engineering, Kyoto University, Nishikyo, Kyoto 615-8540, Japan \\ * Corresponding author: +81-75-383-3921
}

\begin{abstract}
Measurements have been conducted to simultaneously consider both liquid films and droplets of the annular flow on a 3 x 3 simulating BWR fuel rod-bundle test-section with spacers. The optical system of a high speed camera and a tele-microscope was used to record the backlight images at the gap between a corner rod and a side rod of the bundle at high time and space resolutions. The data obtained from the liquid film showed that the mean film thickness, wave height, power spectral density, and wave velocity at the corner rod are larger than those at the side rod, and that the influences of the spacer are different in the cases of low and high gas superficial velocities. Simultaneously, the data containing size and spatial distributions as well as the axial velocity distribution of liquid droplets were obtained. In the case of lower gas flow rates, the spacer generates not only a large number of small droplets but also big droplets whose size exceeds the maximum droplet diameter at upstream. At further downstream, the spatial distribution of the droplets indicates an asymmetry characteristic, which emphasizes the contribution of the droplet impingement mechanism to the entrainment phenomena. Moreover, a close-up observation at right up- and downstreams of the spacer was conducted to describe the interactions between the two-phase flow and this structure. By using these new experimental arrangements, the interaction mechanisms among the wavy liquid film, droplets and spacer were discussed.
\end{abstract}

Keywords: high speed camera; liquid film; droplet; annular flow; spacer; BWR rod-bundle. 


\section{Introduction}

Being the last flow regime that occurs before a possible dryout situation, the characteristics of the annular two-phase flow affect not only the efficiency of the mass and energy transfers but also the safety of many heat exchange systems. This is particularly important in the case of the boiling water reactor (BWR) in which the annular flow does occur near the top of the fuel core. Therefore, all the components of this two-phase flow (such as the liquid film flowing on the rod surface and the liquid droplets flying in the steam core between the rods) as well as the spacer's influences on the flow need to be considered carefully. The annular two-phase flow, however, has caused many difficulties for existing experimental studies because of its highly turbulent characteristics and unstable gas-liquid interfaces.

Many experimental techniques have been conducted to acquire the liquid film’s thickness and wavy characteristics. Existing optical methods, including the planar laser-induced fluorescent (Alekseenko et al., 2009; Schubring et al., 2010; and Farias et al., 2012) and the laser focus displacement (Hazuku et al., 2008), have mostly been applied to circular pipe test-sections. Kamei and Serizawa (1998) used the ultrasonic transmission technique with a rotating reflector for single-rod geometry but this method faced difficulty in detecting large-curvature wavy surfaces. While the x-ray and neutron tomography methods are generally considered complex and expensive, electric conductivity based techniques have become much more popular (Azzopardi, 1986; Feldhaus et al., 2002; Damsohn, 2011; Zhao et al., 2013) because the conductance probes can be applied to a complicated geometry (such as rod bundles) and achieve a very high sampling frequency. However, due to machinery limitations, this method produces very low spatial resolution.

The total volume of liquid droplets of the annular flow can be determined by using suction probes (Barbosa et al., 2002; Kraemer et al., 1995) but details such as the droplet's size and velocity should be obtained by an optical based techniques (Azzopardi, 1997). These optical methods include the laser-diffraction technique (Azzopardi, 1985); the laser anemometry technique (Fore and Dukler, 1995, Yano et al., 2000); and the photography technique (Hay et al., 1998; Cho et al., 2011). Apart from the studies of Yano and Cho (which were conducted with mist flow) the others considered the annular flow in a circular pipe, thus their measuring devices required the removal of the liquid film to detect the droplets flying in the gas core. In other words, the droplet' diameter and velocity could be determined but the wavy characteristics of the liquid film were out of the consideration. 
Several studies mentioned above were conducted to investigate the influences of different spacer designs. Both Feldhaus et al. (2002) and Damsohn (2011) considered the effects of spacers on the liquid film flow in a subchannel test-section. Among the few studies considering the annular flow with a mockup rod-bundle testsection, Nishida et al. (1994) and Kraemer et al. (1995) used circular electrodes and an extraction device, respectively, to measure the liquid film thickness. By treating the entrained droplets with a suction probe as mentioned above, Kraemer's group could consider both liquid film and droplet, but only per the total volume of corresponding liquid.

Most of the previous annular flow experiments have been designed to study only one component of the annular flow: either liquid film or droplet, despite the fact that there is a continuous interchange between the liquid distributed in each of them. Moreover, in the case of rod-bundle geometry, there has been little information on the wavy liquid film's characteristics, especially the interaction between the spacer's structure and the liquid waves. These limitations have restricted a comprehensive understanding of the annular flow phenomena on the rod-bundle geometry with the spacer.

As an attempt to fill in these gaps, the current study is aimed at the following targets:

- To confirm that the high speed camera technique using back light source can be applied to measure both the liquid film and droplets of the annular flow on rod-bundle geometry simultaneously.

- To grasp the characteristics of the wavy liquid film as well as the liquid droplets.

- To improve the understanding of the phenomena happening at the spacer regions.

The visualization arrangement established by Pham et al. (2014) is applied to measure both the liquid film and droplets of the annular flow in a 3 x 3 simulating BWR fuel rod-bundle test-section. The results obtained at high time and space resolutions not only describe the characteristics of the liquid film and droplets in the interactive relationships between them but also indicate the influences of the spacer on the two-phase flow. Furthermore, a close-up observation was conducted at right up- and downstreams of the spacer to describe the interactions between the wavy liquid film and the spacer, as well as the generation of droplets and their behaviors in these regions.

\section{Experimental methodology}

This section describes the experimental apparatus and an attempt to avoid the distortions that can occur in 
1 the image-data of the liquid film and droplets' measurements. After that, the experimental settings used to obtain the close-up qualitative images of phenomena happening at right up- and downstreams of the spacer are presented.

\subsection{Annular two-phase flow loop}

The annular two-phase flow loop (Fig. 1) is similar to the one used in the previous work (Pham et al., 2014). From the water tank, the purified water is pumped to the inlet of the test-section where it meets the gas (normal air) coming from the gas compressor to form the annular flow in the $3 \times 3$ simulating BWR fuel rod-bundle test-section. After that, the two-phase flow moves to the separator where the gas is released into the environment and the water is returned to the water tank.

The test-section consists of a rectangular duct made of transparent acrylic resin and nine steel rods of OD $12 \mathrm{~mm}$ fixed by three circular ferrule-type spacers. A change compared to the system in previous work is that the first spacer is located after the inlet section to increase the rod-fixing capacity of the three spacers. This is necessary to minimize the moving of the rods during the measurement performed at the micro-scale resolutions.

The image data of the liquid film and droplets' measurements are taken by the system of the high speed camera Phantom V7.1 (Vision Research Inc.) and the Cassegrain tele-microscope (Seika Corporation) at four axial positions located before and after the second spacer (Fig. 1). The cross-sections of the test-section, the porous inlet structure, and the specification of the circular ferrule-type spacer are provided in Fig. 2. The image focus plane of the optical system is located at the gap between corner rod \#1 and side rod \#4 as shown in Fig. 2a. All image data of the liquid film and droplets' measurements are taken at this gap only, due to the fact that if the image focus plane of the optical system (DOF $0.5 \mathrm{~mm}$ ) is located further inside the test-section, the existence of the liquid films between the camera and the focal plane (such as the films on rod \#1 and \#4) will cause image distortions. It can be seen in Fig. 2c that the dimples and springs of the spacer are located beyond this gap (three spacers are installed in the same orientation) and therefore they are expected to not cause a local effect on the portions of liquid film located at the gap. Instead, their influences on the measuring data are considered to be embedded in an average effect of the whole spacer structure. The camera system is used to verify the smooth introduction of water to the test-section through the porous inlet structure (Fig. 2b).

While the location of a rod's surface in the image data is calibrated by turning off the valve of corresponding 
1 water line, the physical length represented by each image pixel is determined by taking a photo of a $200-\mu \mathrm{m}$ 2 scale placed at the image focus plane. Then it is calculated that the dimension of an image pixel equals to 6.6 $3 \mu \mathrm{m}$. The accuracy of this measurement method against the influence of light is examined by wrapping a layer made of fluorinated ethylene propylene (FEP) (which has the same refractive index as water) around a rod to simulate the liquid film. The FEP layer's thickness is then measured by a micrometer to be about $0.4 \mathrm{~mm}$. Meanwhile, images captured of the FEP layer are also processed to calculate the layer's thickness. The results of these two measuring methods show agreement within $4 \%$ error. Similarly, the examination for the measurement of liquid droplets is performed by using a one-mm transparent spherical particle to simulate the liquid droplet. The diameters determined by processing the recorded images agree with the ones obtained by the micrometer within 5\% error. However, due to the movement of both liquid film and droplets, the errors in measured data could exceed these values.

Flow conditions of the measurement are chosen based on an observation survey using the camera system as follow: at lower limitations, the gas flow must be strong enough to maintain the upward annular flow and the water flow must be large enough to keep the liquid film from being broken into rivulets. The upper limits are chosen so that the amount of entrained liquid depositing on the acrylic duct wall is not too large to cause a strong distortion in the image data. Finally, twelve flow conditions of four superficial gas velocities, $j_{G}=$ 22.7; 31.8; 44.5; and $62.2 \mathrm{~m} / \mathrm{s}$, and three superficial liquid velocities, $j_{L}=0.020 ; 0.025$; and $0.032 \mathrm{~m} / \mathrm{s}$, are used. Due to a mistake in gathering the image data, the spatial distribution of droplets for $j_{G}=62.2 \mathrm{~m} / \mathrm{s}$ at location $-6 \mathrm{~cm}$ is not available. The gas gage pressure measured near the inlet is about 9.5 ; 15.8; 27.2 ; and $45.2 \mathrm{kPa}$ for the values of $j_{G}$, respectively. The temperatures of the liquid and the gas flows are controlled to maintain the values measured near the inlet at $15 \pm 0.5^{\circ} \mathrm{C}$ and $16 \pm 1^{\circ} \mathrm{C}$, respectively.

\subsection{Problem of image distortion}

A challenge that must be overcome is that the images taken through the acrylic duct wall can be distorted by the amount of liquid possibly distributed on this surface, especially when the entrainment rate is high or when there is a spacer placed between the inlet and the measuring point. To minimize these distortions, an oval-shape obstacle made of commercial tape and silicon is setup onto the inner surface of the duct wall to guide the liquid (if there is any) around the image windows (Fig. 3). The thickness of this obstacle is quite 
1 small ( $\sim 0.8 \mathrm{~mm})$ and it is placed locally at the image window so its influences on the two-phase flow from the

2 inlet to the measuring point is expected to be negligible. It should be noticed that this modification only affects

3 the amount of liquid distributed on the duct wall, not the liquid films flowing on the rods' surfaces that are

4 under consideration. Similar attempts would not be accomplished in the case of circular-pipe test-section in 5 which the main liquid film flows on the duct wall.

However, it should be noticed that the image distortions cannot be absolutely avoided by using the ovalshape obstacle. This is because the entrained droplets still have a possibility to deposit onto the acrylic ductwall area located inside this structure. When this happens, unrealistic values will usually show up in the acquired data, such as very large liquid film thickness and droplet diameters. Hence, the outputs of the image auto-processing procedures described in Section 3 will need to be plotted and reviewed manually to find these strange points (if there are any), and correct them based on the observation of corresponding video frames. Due to the large amount of data generated by the high speed camera, this task costs time.

\subsection{Close-up observation of phenomena happening near spacer}

Beside the quantitative measurements of the liquid film and droplets, a close-up observation at the second spacer (Fig. 1) is also conducted to understand the phenomena happening at right up- and downstreams of this structure. However, the attempt to avoid the image distortions by using an oval-shape obstacle mentioned above cannot be accomplished, because the existence of the spacer itself offers a pathway for the liquid to flow from the rod surface onto the duct wall and cover the image window. Therefore the task requires the water supply at six rods (\#1, 3, 4, 6, 7, and 9) to be turned off as indicated in Fig. 4, and the first spacer to be removed in order to minimize the amount of liquid distribution on the duct wall. The $j_{G}$ conditions are the same as the settings of droplet measurement. The water flow rates at the inlets of each of the three working rods (\#2, 5, and 8) are also the same as that of each of the nine rods in the droplet measurement experiment, therefore the water superficial velocity in this observation will be denoted as $j_{L \times 3}$ to hold the same values as before. The image focus plane is setup at the gap between the side (\#2) and the center (\#5) rods (Fig. 4), and the axial locations of the close-up observation are as indicated in Fig. 1. The camera's recording speed and image windows are changed depending on the process under consideration.

With the absence of water at the six rods mentioned above and the moving of image focus plane into the 
1 gap between side rod (\#2) and center rod (\#5), the liquid film and droplets observed in this task have different

2 characteristics compared to those in the case of quantitative measurements performed at the gap between corner rod (\#1) and side rod (\#4). However, the phenomena happening locally such as the interactions between the spacer cell and the liquid film or droplets are expected to share some common features. This close-up observation is aimed to grasp these phenomena.

\section{Image data acquiring and processing}

\subsection{Measurement of liquid film and wave velocity}

The 64 x 512 pixels image window is used to trace the gas-liquid interface at recording speeds from 17 to $32 \mathrm{kfps}$, corresponding to the increasing of gas superficial velocity. These setting are decided after a survey to make sure that the recording speed is enough to detect all wave crests passing by the image window. Due to the large amount of image data generated at the high recording speed, the total recording time of each flow condition and measuring position is limited to 5 sec. Depending on the recording speed, from four to eight shots are taken in each case.

The image-data processing procedure used in the measurement of the liquid film is presented in Fig. 5 as follows:

(0) Original image with corner rod (\#1) and side rod (\#4) located in the left and the right hand sides, respectively.

(1) The integrated Canny’s edge-detection operator (Canny, 1986) is used to detect the edges where sharp changes of intensity occur in the original image. The small values of both lower and upper thresholds of this operator are chosen to detect not only the strong edges but also the weaker ones. 
(2) The detected edges that belong to the droplets are removed. The method used to locate the droplets' image area is presented in Section 3.2.

(3) Among the remaining edges, the strongest one of each side is selected by comparing the gradient of image intensity across them to represent the corresponding film surface.

(4) The liquid film thickness is determined by the distance between the rod surface and the interface point located on the middle pixel-row of the image.

It can be seen in the image of step (1) that Canny's edge detection operator also detects weak edges (indicated by several short lines), causing the selection of the strongest edge for each side at step (3) to require additional computational time. However, it is necessary to use the small thresholds of this operator because the background of the images continuously changes with time and will also be different for each flow condition and measuring position. Hence, there are cases in which the real film surface belongs to a weak edge. By covering these situations, just one set of thresholds is needed for the wide range of light and background conditions. For the cases in which the wave height at both sides are large enough to touch each other (liquid bridge formation), this image processing procedure would not detect any interface and therefore, the film thickness at each side would be assigned to the last detectable thickness value. This behavior is expected to not have a significant influence in the obtained results, because the survey of the image data shows that this liquid bridge formation rarely happens, and the bridges only exist in a very small number of image frames.

Because the data are recorded at high speed, the shapes of the recorded waves do not change much when they pass by the narrow image window, the film thickness calculation procedure is therefore able to take only the middle pixel-row of the image into consideration to save data processing time. Meanwhile, the wave velocity measurement uses the $7^{\text {th }}$ and $57^{\text {th }}$ rows. A cross-correlation between the time-resolved thickness series obtained at these two locations is then calculated. The time-lag corresponding to the peak of the correlation (as seen in Fig. 6) is the average period of time needed for the waves to travel between these pixel-rows. To increase the accuracy in the determination of the time-lag, a sub-time-step interpolation of the cross-correlation is performed. Then the wave velocity is determined by using the real distance of $330 \mu \mathrm{m}$ and the time-lag (in sub-step resolution). Previously, this method was also used by Farias et al. (2012) with a laser-induced fluorescence technique. In the current experiment, the time-lag equivalents to about 10 to 20 sub-time-steps depending on the flow condition and recording speed, and the error of the velocity measurement is estimated to be less than $15 \%$. 
Compare to other techniques that use two sensors, such as the conductance probes (Azzopardi, 1986) or the photo cells (Hurlburt and Newell, 1996), the current velocity measurement method presents a better approach because the shape of the waves is changed very little when they move between two pixel-rows. Meanwhile, the physical probes are not small enough to be put closely together due to machinery limitation. This advantage becomes important in the case of high gas flow rates, in which the wavy surfaces become more unstable.

\subsection{Measurement of liquid droplets}

Image data of the liquid droplets' diameter and spatial distribution are acquired by using 512 x 512 pixels image window. A low recording speed of $200 \mathrm{fps}$ is used to avoid the situation in which a low-speed droplet appears in more than one image frame. With the height of the image $\sim 3.38 \mathrm{~mm}$, this requirement is satisfied for droplets traveling faster than $0.68 \mathrm{~m} / \mathrm{s}$. Because this value approximates the lower limit of the mean wave velocity of the liquid film (as will be seen in Section 4.1.3), all droplets flying in the gas core are expected to have a velocity higher than $0.68 \mathrm{~m} / \mathrm{s}$. Five shots are taken for each flow condition and measuring point to obtain a total recording time of 10 sec.

The image processing procedure used in the measurement of the liquid droplets is described in Fig. 7 as follows:

(0) The original 512 x 512 pixels image taken just after a droplet impingement event is selected as an example to show the ability to detect small-diameter droplets of the current method.

(1) The edges present in the original image are also detected by the integrated Canny's edge-detection operator. A set of low and high thresholds of this operator are chosen after surveying the image data of different flow conditions. This set is then applied to all flow conditions and measuring points. It should be noted that the thickness of the edge detected by Canny's algorithm is one pixel.

(2) All image areas bounded by a closed edge line are determined and marked as droplets. With an estimated DOF of about $500 \mu \mathrm{m}$, the noise caused by the liquid film flowing on the duct wall behind the focus plane, as well as by droplets being partly or fully out of the DOF would not have a fully clear boundary and hence will not be included in the data.

(3) A removal of single-open lines in the image is performed so that only droplets' image areas remain.

(4) Each droplet's image area's equivalent diameter and distance from the centerline of the gap of the 
two rods are calculated to represent the corresponding droplet. The points marked by the letter $\mathrm{D}$ present in most of the image frames correspond to the dust-points in the optical system and will be removed by a comparison between the frames.

The droplet velocity measuring method also uses the same procedure to detect droplets in all image frames but uses a much higher recording speed, because each droplet needs to be detected at least two times. Based on the distribution of droplet size obtained with the 512x512 pixels image-window, various width values are chosen to balance between the recoding speed and the width of the image window. Keeping the image height of 512 pixels, the width is set between 144 and 64 pixels - corresponding to the increasing of gas superficial velocity - to achieve the recording speed from 17 to $32 \mathrm{kfps}$. About 10 shots are taken for each flow condition and measuring point to obtain the recording time of 5 sec.

After detecting all droplets in the obtained image series, the existence of a droplet in two successive frames is determined by comparing the equivalent diameter, distance from the central line of the gap, and average image intensity of each droplet found in these two frames. This study considers only droplets flying almost parallel to the central line (the difference between the radial positions in two frames is less than five image pixels). The droplet velocity is calculated from the difference between its axial positions in the two frames and the image recording speed. If the same droplet is detected several times, the first two frames are used.

\subsection{Limitation of the measurements}

The detection of gas-liquid interfaces and droplet boundaries adapts to the spatial resolution of $6.6 \mu \mathrm{m}$ per pixel. It can be seen that because the measurement is performed at the micro-scale of resolution, any relative displacement between the camera system and the rods' surface, however small, could affect the accuracy of the obtained data, especially for the liquid film thickness. With the current apparatus, changes in liquid flow rates might change the weight of, or the pressure inside, the test-section, which in turn would cause the rods to bend. As a result, the position of the rods' surfaces are seen to be displaced a distance up to four image pixels (or 27 $\mu \mathrm{m})$ between the no-water condition (to detect the rod surface) and the working flow conditions. Therefore, it is necessary to include this distance (adding or subtracting) into the measured thickness. Because of this limitation, the current data can be used to study average film thickness and large-amplitude waves but they are 
1 not suitable to make the discussion on the minimum liquid film thickness. This problem, however, would be solved in the next version of the apparatus by improving the test-section and the fixing of the camera system.

For the measurement of liquid droplets, the definition that a droplet is the image area bounded by a closed boundary edge allows the detection of droplets whose equivalent diameter is as small as three pixels. However, the detection of these small droplets can be affected by the image background. With this study's backlight condition, the small droplets are hardly able to cause clear dark image areas that can be distinguished from the background so as to be detected by the detection operator. Currently, the lower limit of equivalent droplet diameter needs to be set at four pixels to remove this uncertainty. However, this limitation can also be improved by adding another oval-shape obstacle onto the duct wall behind the focus plane (the design of the test-section in this study has not allowed this modification).

The algorithm of finding the same droplet in two successive frames used in the droplet velocity measurement cannot recognize the case in which a droplet detected in the current frame disappears in the next frame (due to non-vertical velocity component) and another one is detected instead due to similarities in diameter, image intensity, and radial position. Then an incorrect velocity will be calculated based on the difference between their axial positions and the obtained value can be unreasonably lower or higher. However, the likelihood of this situation is small due to the thin DOF and the small image area, therefore it does not affect the statistical point of view, but the information for minimum and maximum droplet velocities cannot be obtained. Instead, the velocity measurement uses the liquid film wave velocity (Section 4.1.3) and $1.5 j_{G}$ as the lower and upper limits of the droplet velocity, respectively. Furthermore, with the exposure time of the camera reduced to $2 \mu$ s for all data recording and the highest recording speed is $32 \mathrm{kfps}$ (or the minimum time step of $31.25 \mu \mathrm{s})$, the error of the droplet velocity measurement is less than $6.4 \%$.

It also needs to be pointed out that the backlight arrangement only allows for measurements at positions through which the light source can be seen by the camera. This limitation restricts the current method from providing data of average variables for the whole flow area.

\section{Results and discussion}

The next two subsections present the measurement results of the liquid film and droplets, respectively. The influences of both the flow conditions and the spacer on the two-phase flow, and the effects of the liquid film's 
1 characteristics on the droplet distributions are discussed. After that, the qualitative visualization image-data taken near the spacer are provided to describe the spacer-flow interactions and explain the mechanism behind the creations of liquid droplets.

\subsection{Characteristics of liquid film}

Firstly, examples of the disturbance waves’ signals obtained at different gas flow rates are presented in Fig. 8. These thickness time-series are confirmed by visualization data to correspond to disturbances waves, which possess large amplitudes and generate liquid droplets continuously through various entrainment mechanisms mentioned in Pham et al. (2014). Qualitatively, as $j_{G}$ increases, both the height and time scale of the disturbance waves decrease and the gas-liquid interface becomes less gentle. It can also be seen that the disturbance waves appear as batches of many crests, so the use of wave height based on local maxima or large wave counting to analyze the waves’ characteristics might not be suitable for this study's flow conditions and measuring resolutions. Quantitative data including average values, probability density, power spectral density of liquid film thickness, and wave velocity are given in the next subsections.

\subsubsection{Liquid film thickness}

The data of average values and probability density functions of liquid film thickness obtained in all flow conditions and measuring positions are presented in Figs. 9 and 10, respectively. Both of them show the wellknown tendency in which the mean film thickness increases when $j_{L}$ increase and decreases when $j_{G}$ increase. It should be noticed that the horizontal axis of film thickness in Fig. 10 has been cut off at $800 \mu \mathrm{m}$ (for the corner rod) and $700 \mu \mathrm{m}$ (for the side rod) to magnify the region near the peak of the distribution.

One important point which agrees well with the data obtained by Nishida et al. (1994) is that the liquid film flowing on the corner rod is thicker than that on the side rod. Beside the possible interactions of the two-phase flow between the rods and the duct wall, this trend could be explained based on the velocity profile of the gas phase. Unfortunately, this information is neither available in the current experiment nor in the literature, so the discussion must be realized on the single-phase flow data. An experiment considering the single-phase flow in a 5 x 5 rod-bundle test-section with spacers performed by Dominguez-Ontiveros et al. (2012) showed that a rod located closer to the center of the bundle will get exposed to higher velocity flow. The similar feature was 
also seen in the data of 2 x 3 rod-bundle experiments performed by Renksizbulut and Hadaller (1986), and by Shin and Chang (2009). Taking this point of view, the neighbored gas velocity around the current experiment's corner rod (\#1) would be smaller than that of side rod (\#4). Due to this difference, the liquid film on the corner rod would be thicker than on the side rod.

When the two-phase flow passes through the spacer region, both the gas core and the liquid film will interact with the spacer structure and the obtained data show different trends for the lower values (22.7 and $31.8 \mathrm{~m} / \mathrm{s}$ ) and higher values (44.5 and $62.2 \mathrm{~m} / \mathrm{s}$ ) of $j_{G}$ (Fig. 9). As an attempt to explain this inconsistency, we consider the following three possible phenomena that could affect the film thickness measured at the gap between two rods:

(1) Due to the interaction between the liquid film and the spacer, an amount of liquid is separated from the film and flows along the spacer's structure (including spacer cells, dimples and springs) to the duct wall, or gets ripped off of the top of this structure to form liquid droplets. This separation reduces the liquid film thickness and will become more important at higher gas flow rates, which causes higher liquid momentum.

(2) As indicated in the simulation work of Jayanti and Rajesh Reddy (2013), which considered the effect of spacer grids on the single phase flow in rod-bundle geometry, the spacer reduces the gas velocity in several regions behind it, especially at each of the gaps between two rods. This also creates higher velocity regions at the neighboring subchannels. In turn, the distribution of liquid around each rod right after passing through the spacer is modified due to the changes in gas velocity occurring nearby: the liquid film portion located at the gap right next to the spacer becomes thicker while the others become thinner. At further downstream, Jayanti and Rajesh Reddy's simulation work also indicated that a recovering of gas velocity profile would occur and a more uniform liquid distribution would be achieved. If the measuring point falls inside this recovery region, large thickness values will be recorded at the gap. Naturally, the recovering process will be faster at higher gas flow rates.

(3) The increase in the liquid film's thickness as it moves downstream might be due to the droplets previously generated by the separation effect mentioned in (1) depositing back onto the film surface, or due to the friction loss of the flow.

A combination of these processes is expected to make a total effect on the measured film thickness. Depending on the flow condition and axial position, any one of these processes could be more prominent in 
1 determining the tendency of the measured film thickness. For the data of the lower values of $j_{G}$, the thickness 2 measured at $10 \mathrm{~cm}$ is larger than that at $-6 \mathrm{~cm}$ because the modification effect on the liquid film as mentioned 3 in (2) is more prominent than the separation effect. Then the lower values at $26 \mathrm{~cm}$ expresses that the recovering process has been accomplished before this point. The decrease in value at $26 \mathrm{~cm}$ compared to that at $-6 \mathrm{~cm}$ is caused by the loss of water in the separation effect (1). From 26 to $42 \mathrm{~cm}$, the thickness is increased mostly by the processes presented in (3).

In the cases of higher values of $j_{G}$, the modification and recovering processes mentioned in (2) could be accomplished more quickly. The measured thickness at $10 \mathrm{~cm}$ is smaller than that at $-6 \mathrm{~cm}$ mostly due to the separation effect. Then the measured thickness increases as the liquid moves downstream due to the droplet deposition and friction loss. It can be stated that for the current range of $j_{L}$ and test-section, there is a transitional point of gas superficial velocity, falling between 31.8 and $44.5 \mathrm{~m} / \mathrm{s}$. For the convenience of the discussions later, the values of $j_{G} \leq 31.8 \mathrm{~m} / \mathrm{s}$ and $j_{G} \geq 44.5 \mathrm{~m} / \mathrm{s}$ will be classified as low and high superficial gas velocities, respectively.

The root mean square (RMS) values of the liquid-film thickness fluctuations are presented in Fig. 11. Similar to the mean liquid film thickness, the RMS increases when $j_{L}$ increase and decreases when $j_{G}$ increase. Furthermore, it can be observed from the data that the magnitudes of waves at the corner rod are larger than those at the side rod.

\subsubsection{Power spectral density}

The power spectral density (PSD) of time-resolved film thickness is calculated by using Matlab’s functions. The cases presented in this section are purposefully selected among the entire data to show the influences of the changes in gas and liquid superficial velocities, as well as measurement positions, on the waves' characteristics. Fig. 12 shows the PSDs obtained in all flow conditions at $-6 \mathrm{~cm}$. It should be noted that the scale of the vertical axis is different for each $j_{G}$. The power scale decreases with the increasing of $j_{G}$ and/or $j_{L}$ in the same tendency of liquid film thickness mentioned in Section 3.1. This trend was also observed by Farias et al. (2012) with a horizontal test-section. When $j_{G}$ increases, the peak frequency is seen to move to higher regions and the spectral becomes flatter because the energy is distributed in a broader range of frequency, as explained by Paras et al. (1991). On the other hand, the increase of $j_{L}$ seems to cause lower peak frequencies due to the appearance of larger wave structures at lower frequencies. 
The PSDs obtained at different axial positions on the corner and side rods for low and high superficial gas velocities are presented in Fig. 13. It can be seen that the PSDs obtained at the side rod for all measuring points and gas flow rates are at a lower scale than those at the corner rod. This is in relation to the fact that the side rod's film thickness is smaller, as seen in Section 3.1.

An interesting occurrence was observed pertaining the difference between the trends of the PSDs and the mean liquid film thickness at the corner rod during high $j_{G}$. While the peak region of PSD observed at $-6 \mathrm{~cm}$ disappears at $10 \mathrm{~cm}$ and then appears again at $26 \mathrm{~cm}$ (Fig. 13), the mean thickness decreases across the spacer (from $-6 \mathrm{~cm}$ to $10 \mathrm{~cm}$ ) and then maintains its low value until the next measuring points $(26 \mathrm{~cm}$ and $42 \mathrm{~cm}$ ), as seen in Fig. 9. The recovery of the PSD peak region at $26 \mathrm{~cm}$ without an increase in mean liquid film thickness could be associated with the development of disturbance waves, in which a coherence of smaller disturbance wave structures happens to form larger waves (Zhao et al., 2013; Pham et al., 2014). According to Azzopardi (1986), if a flow predominantly features disturbance waves, the PSD peak region will correspond to the frequencies of these wave structures. Therefore, it can be stated that when the disturbance waves pass by the spacer region, their structures will be broken.

On the other hand, the spacer appears to have little influence over the PSD obtained at the side rod during high $j_{G}$. This seems to contradict with the fact that the mean film thickness obtained at this rod follows the same trend of that at the corner rod (Fig. 9), and the PSD at this rod is confirmed to grow with the increase of $j_{L}$ and vice versa (Fig. 12). However, it should be noted that all the PSD data presented in Fig. 12 are obtained at one position $(-6 \mathrm{~cm})$, hence the influences of axial position are not included. Meanwhile, the development of disturbance waves downstream from the spacer to the $10 \mathrm{~cm}$ point does exist (Zhao et al., 2013 and Pham et al. 2014) and should contribute to the PSDs obtained at $10 \mathrm{~cm}$. This could somehow compensate the decrease of the PSD at the side rod across the spacer and thus, the PSD obtained at $10 \mathrm{~cm}$ does not change much compared to that at $-6 \mathrm{~cm}$. A similar PSD development is expected to occur at the corner rod but it could take a longer distance to achieve a high PSD (until $26 \mathrm{~cm}$ ).

\subsubsection{Mean wave velocity}

The mean wave velocities obtained by processing the time-resolved data are presented in Fig. 14. As a general trend which was also observed by Jayanti et al. (1990) and Farias et al. (2012) for horizontal testsections, the data indicate that the wave velocity increases with the increasing of $j_{G}$ and/or $j_{L}$. The faster gas 
1 flow transfers more momentum to the liquid film surface, leading to a faster wave velocity. The increase of 2 liquid flow rate results in higher liquid film thickness, which facilitates the generation of more waves with 3 higher wave velocity. Both the spacer and axial position however, do not present a clear influence on the mean wave velocity. Taking the measurement error of about $15 \%$, the wave velocity seems to not change much when the film passes by the spacer and flows further downstream.

The mean wave velocities at the corner rod are seen to be higher than those at the side one. This seems to conflict with the influences of the gas velocity profile mentioned above, in which the gas surrounding the side rod flows faster than that of the corner rod, giving more momentum to the side rod's liquid film. As shown in Fig. 11, however, there are more large-amplitude wave structures on the corner rod. These larger waves are well known to travel faster than the smaller ones (Schubring et al., 2010b; Farias et al., 2012). Therefore, the mean wave velocity measured at the corner rod can be reasonably higher than that at the side rod.

\subsection{Characteristics of liquid droplets}

\subsubsection{Droplet size distribution}

Fig. 15 presents the droplet size distribution for all flow conditions and measuring points. Among these four measuring locations, it can be expected that the effects of flow conditions in the obtained data are clearest at upstream of the second spacer (at $-6 \mathrm{~cm}$ ). The data show a common tendency in which the number of droplets is increased with the increasing of $j_{G}$ and/or $j_{L}$. While the increase of $j_{G}$ means higher wave velocity or momentum, the increase of $j_{L}$ directly relates to the magnitude of waves existing at the liquid film surface, as shown in Fig. 11. Both of them would enhance the entrainment processes occurring at the gas-liquid interfaces, as described in Pham et al. (2014).

Generally, the size distribution of entrained droplets is determined by a combination of the bag and ligament break-up processes. According to Azzopardi (1997), the occurrence possibility of ligament break-up events is increased as $j_{G}$ decreases or $j_{L}$ increases. This mechanism generates smaller number of droplets but with larger sizes compared to the bag-breakup process (Pham et al., 2014). Therefore, the quantity of big droplets flowing in the gas core increases as $j_{G}$ decreases or $j_{L}$ increases, as shown in Fig. 15.

The spacer's influence can easily be seen by comparing the data obtained at -6 and $10 \mathrm{~cm}$. In all flow conditions, the spacer generates not only several big droplets whose diameters exceed the maximum droplet 
1 diameters at upstream but also a huge number of smaller droplets which causes the counting peak to move

2 slightly towards the smaller diameters. The appearance of these large size droplets can be linked to the 3 theoretical "run-off" effect in which the liquid distributed on the spacer surface flows upward and leaves this structure (Yano et al., 2001a). The creation of small droplets was considered by Cho et al. (2011) a result of the interaction between the droplets existing upstream and the spacer grid, but in a study for mist flow regime. It actually requires more information on the phenomena happening at the spacer to understand the mechanism controlling the droplet size distribution. Therefore, a more detailed discussion on this point will be given in Section 4.3 along with visualization data.

\subsubsection{Spatial distribution of droplets}

The spatial distribution of liquid droplets in the gap between the corner and side rods is provided in Fig. 16. At upstream of the spacer, the droplets are distributed quite uniformly in the gap. Then the spacer introduces a large number of droplets into the gas core as indicated by the data at $10 \mathrm{~cm}$. At further downstream, the droplet count decreases, suggesting that the rate at which droplets deposit or leave the DOF of the image window is larger than that of the droplet generation.

The most interesting point indicated by the data is the asymmetric distribution of droplets in further downstream of the spacer. The data obtained at $10 \mathrm{~cm}$ for all flow conditions are still almost symmetric, but shortly after this point the peaks are clearly seen to move towards the corner rod (at the left hand side of the plots), especially at higher gas superficial velocities. One possible explanation is the interaction between the gas flow and the liquid films at both sides of the gap. The data of the liquid film presented in Section 4.1 show that both average film thickness (Fig. 9) and wave height (Fig. 11) are larger at the corner rod. Therefore, the frequency of the bag and ligament break-up events (Azzopardi, 1983, 1997; Pham et al., 2014) should be higher at this rod, causing more droplets to be generated than at the side rod. This argument, however, does not hold with the data at $-6 \mathrm{~cm}$ where the difference between the wave magnitudes at both sides clearly exists but the droplet distribution is quite homogenized.

Instead, the high droplet population itself can be responsible for the asymmetry effect. Beside the bag and ligament break-up processes, droplets can also be generated through the droplet impingement mechanism, in which a droplet flying in the gas core impinges on the wavy film surface, creating secondary droplets (Ishii and Grolmes 1975). The occurring frequency of this process increases as the droplet count increases. According 
1 to the side-view images obtained by Pham et al. (2014), the amount of entrained liquid in the form of secondary

2 droplets can be significant. This amount is determined by the impact angle, and is proportional to the 3 momentum of the primary droplets, in a way similar to a typical droplet impact event. Because the velocity vectors of the primary droplets are almost parallel to the rod surface, the high-amplitude waves on the corner rod present a larger impact angle. So when these droplets impinge against the liquid film's waves, they give that portion of liquid a lot of kinetic energy, and as a result increase its possibility of being entrained into the gas core. In contrast, small waves or smooth surfaces provide small impact angles, which restrict this entrainment process.

Therefore, the impingement processes that occur between the high-density droplet flow and the wavy liquid film on the corner rod will generate a larger number of secondary droplets than on the side rod, which has a smoother liquid surface. It can be seen in the data that the asymmetry is clearer at higher $j_{G}$ (meaning higher droplet momentums) and further downstream, where more and more droplets have taken part in the impinging or depositing processes. The data obtained at small values of $j_{G}$ on the other hand, do not possess a clear asymmetry shape due to the low density and momentums of the droplets. This new information quantitatively points out the important contribution of the droplet impingement mechanism in the entrainment phenomena of the annular two phase flow, which has not been emphasized in previous literatures.

\subsubsection{Droplet velocity}

The probability density functions of droplet velocity and the dependence of the velocity on the droplets' diameters for all flow conditions and measuring points are presented in Figs. 16 and 17, respectively. It is necessary to point out that the number of successful droplet velocity detections for low gas velocities or at upstream of the spacer is not enough for statistical consideration. However the effects of the flow conditions on the distribution of velocity can still be observed. Unlike the results obtained at the centerline of a circular pipe test-section by Fore and Dukler (1995), the droplet velocity in this experiment does not significantly exceed the superficial gas velocity. It is because the gas velocity at the gap between two rods does not belong to the highest values of the gas velocity profile as in the case of their experiment.

The changes of gas velocity through the spacer based on the single phase profile mentioned in Section 4.1.1 are also reflected. The low gas velocity at the center of the gap at downstream of the spacer $(10 \mathrm{~cm})$ could be one reason for the droplets' lower velocity compared to the values at upstream $(-6 \mathrm{~cm})$. Further downstream of 
the spacer, there is a general trend in which the peak velocity slightly increases because the droplets are accelerated by the gas flow. On the other hand, the existence of small velocity values should correspond to the droplets that were generated near the measuring points and have not accelerated.

\subsection{Close-up visualization of spacer-flow interactions}

The quantitative data of the liquid film and droplets presented above have pointed out the influences of the spacer on the two-phase flow. This subsection provides close-up observations of the phenomena happening right up- and downstreams of this structure. Firstly, Fig. 19 shows the images taken in these regions when all the water valves are closed. The angle of the optical system is slightly adjusted to allow the visualization of not only the surfaces of the side and corner rods but also the portions of the spacer-cells holding them. The image data presented below are subjectively selected to show typical situations of the interactions between the two-phase flow and the spacer cells. In this manner, the time-step of each image series is chosen based on the speed of progression of the phenomenon being considered. The brightness and sharpness of most of the images are slightly adjusted to enhance visual quality.

Two situations in which large-amplitude waves approach the spacer are shown in Fig. 20. In both cases of low and high values of $j_{G}$, the wavy films can smoothly enter the spacer region even when there are some wave crests excess the rod-spacer clearance. It is necessary to mention that the droplets that exist in several frames of Fig. 20 (Fig. 20a at $242 \mu$ s, and Fig. 20b at 242 and $363 \mu$ s) are commonly observed whenever disturbance waves pass by the image windows. This is because the disturbance waves themselves continuously generates droplets as they move downstream regardless of the existence of the spacer (Pham et al., 2014). In other words, the interruption of the spacer hardly causes any separation in which an amount of liquid in the film is immediately detached and put into the gas core. Hence, the increase of liquid entrainment at a region located right upstream of the spacer mentioned in the “narrow channel effect” model (Yano et al., 2001a, 2001b) seems to not exist in the current study's image data. Instead, some amount of liquid leaves the liquid film and moves onto the spacer's surfaces to flow on. When the liquid reaches the end of the spacer, the creation of liquid droplets happens as shown in Fig. 21. From the obtained visualization data, the frequency of these droplet generations is clearly seen to be much higher than that of large-amplitude waves entering the spacer (Fig. 20). This is because of the existence of the spacer's dimples and springs (Fig. 2c), which provide pathways from 
1 the rod surface to the spacer cells. Following these pathways, some portions of liquid that belong to the base 2 film (not necessary the large-amplitude waves) can easily move onto the spacer surface. Therefore, it can be concluded that the amount of liquid distributed in the droplets after the spacer mostly comes from the base liquid films.

At low $j_{G}$ (Fig. 21a), a process similar to the bag break-up mechanism does happen to the liquid block attached to the top of the spacer structure and small-size droplets are generated, but the formation of thick ligaments which are subsequently broken into large-size droplets occurs much more frequently. Meanwhile the image series in Fig. 21b shows that for high $j_{G}$ the bag break-up mechanism dominates the droplets generation processes. In this mechanism, large amount of small-size droplets are formed first as the bag-shapes are broken and then the larger ones are formed from the breaking of the rims. Because the rims are similar to a thin ligament, the droplets of the latter group are small compared to the droplets generated in the case of low $j_{G}$. This is the main reason why the droplet-size distribution of low $j_{G}$ consists of large droplets, which are not found in the cases of high $j_{G}$, as seen in Fig. 5.

The typical behaviors of liquid droplets in the regions up- and downstreams of the spacer are also observed. Fig. 22a shows a collision between a droplet and the spacer cell. Despite the small thickness of the spacer cell (500 $\mu \mathrm{m})$, impacts like this are frequently found in the image data, during which splashing occurs and the primary droplet is broken into many tiny secondary ones. These small-size droplets even bounce back in the next two frames $($ at time $=117 \mu$ s) before being pushed up by the gas flow. This large number of small droplets can keep a role in the size distribution of the droplet after the spacer.

An interesting situation commonly observed at right downstream of the spacer is when a droplet keeps rotating at the same elevation, or even falling down, despite the high gas superficial velocity flowing in the system. As seen in Fig. 22b, several droplets hold their axial positions or even fall down for a while before one of them undergoes the bag break-up process. This indicates that some flow areas in the spacer region are temporarily blocked due to the formation of liquid bridges. When these flow areas are opened again, the exposing of a zero-velocity droplet to a local high-velocity gas flow easily leads to a droplet break-up process.

Fig. 22c also describes the case of a droplet falling down but after that it undergoes the ligament break-up process. It is well known that the type of break-up that the droplet will go through is determined by the local gas velocity and its size. Because the local gas velocity continuously changes with time, both mechanisms are expected to occur in this region. However, while the ligament break-up processes only generate several droplets 
1 of smaller size compared to the original one, the bag break-up events can add a large number of tiny droplets

into the gas core. Therefore, beside the collisions between the upstream-droplets with the spacer-cell mentioned above, the bag break-up process is also responsible for the huge number of small-size droplets further downstream of the spacer, as seen in Fig. 15.

\section{Conclusions}

The quantitative data presented in this paper have confirmed the advantages of applying the high speed camera with back light technique to simultaneously study both the liquid films and droplets of the annular flow on rod-bundle geometry with spacer. The main conclusions made from the obtained data are as follows:

- The average liquid film thickness, wave amplitude, and wave velocity measured at the corner rod are higher than those at the side rod.

- At upstream of the spacer, the droplet's population and size distribution directly relate to the magnitude of waves existing on the liquid films because most of them are generated through the entrainment processes.

- The spacer generates a huge number of small-size droplets and, in the case of low gas superficial velocity, several droplets whose diameters exceed the maximum droplet diameter at upstream.

- The asymmetrical spatial distribution of the droplets at downstream of the spacer quantitatively emphasizes the important contribution of the droplet impingement processes to the liquid entrainment phenomena.

The close-up visualization conducted near the spacer has successfully provided detailed information of the phenomena happening at right up- and downstreams of this structure. At both low and high gas superficial velocities, the spacer region lets large-amplitude waves enter smoothly instead of enhancing the liquid entrainment processes. The obtained images of the generation of droplets and their behaviors right downstream of this structure explain well the mechanisms behind the size distribution, which consists of several large droplets and a huge number of small-size ones.

Future work will include improvements in the fixing capacity of the optical system, and will also feature two oval-shape obstacles on the walls at both sides of the test-section in order to reduce background noise. The same measurement set up and close-up visualization will be applied to study the influences of different types 


\section{References}

Alekseenko, S., Antipin, V., Cherdantsev, A., Kharlamov, S., Markovich, D., 2009. Two-wave structure of liquid film and wave interrelation in annular gas-liquid flow with and without entrainment. Phys. Fluids 21, 061701.

Azzopardi, B.J., Mechanisms of entrainment in annular two-phase flow. UKAEA Report AERE-R 11068, 1983.

Azzopardi, B.., 1986. Disturbance wave frequencies, velocities and spacing in vertical annular two-phase flow. Nucl. Eng. Des. 92, 121-133.

Azzopardi, B.J., 1985. Drop sizes in annular two-phase flow. Exp. Fluids 59, 53-59.

Azzopardi, B.J., 1997. Drop in annular two-phase flow. Int. J. Multiph. Flow 23, 1-53.

Barbosa, J.R., Hewitt, G.F., König, G., Richardson, S.M., 2002. Liquid entrainment, droplet concentration and pressure gradient at the onset of annular flow in a vertical pipe. Int. J. Multiph. Flow 28, 943-961.

Canny, J., 1986. A computational approach to edge detection. IEEE Trans. Pattern Anal. Mach. Intell. 8, 679-98.

Cho, H.K., Choi, K.Y., Cho, S., Song, C.-H., 2011. Experimental observation of the droplet size change across a wet grid spacer in a 6×6 rod bundle. Nucl. Eng. Des. 241, 4649-4656.

Damsohn, M., Prasser, H.-M., 2011. Droplet deposition measurement with high-speed camera and novel high-speed liquid film sensor with high spatial resolution. Nucl. Eng. Des. 241, 2494-2499.

Dominguez-Ontiveros, E.E., Hassan, Y. A., Conner, M.E., Karoutas, Z., 2012. Experimental benchmark data for PWR rod bundle with spacer-grids. Nucl. Eng. Des. 253, 396-405.

Farias, P.S.C., Martins, F.J.W. A., Sampaio, L.E.B., Serfaty, R., Azevedo, L.F. A., 2012. Liquid film characterization in horizontal, annular, two-phase, gas-liquid flow using time-resolved laser-induced fluorescence. Exp. Fluids 52, 633-645. 
Feldhaus, G., Azzopardi, B.J., Zeggel, W., 2002. Annular flow experiments in rod bundles with spacers. Nucl. Eng. Des. 213, 199-207.

Fore, L.B., Dukler, A.E., 1995. The distribution of drop size and velocity in gas-liquid annular flow. Int. J. Multiph. Flow 21, 137-149.

Hay, K.J., Liu, Z.-C., Hanratty, T.J., 1998. A backlighted imaging technique for particle size measurements in two-phase flows. Exp. Fluids 25, 226-232.

Hazuku, T., Takamasa, T., Matsumoto, Y., 2008. Experimental study on axial development of liquid film in vertical upward annular two-phase flow. Int. J. Multiph. Flow 34, 111-127.

Hurlburt, E.T., Newell, T. a., 1996. Optical measurement of liquid film thickness and wave velocity in liquid film flows. Exp. Fluids 21, 357-362.

Ishii, M. Grolmes, M.A., 1975. Inception Criteria for Droplet Entrainment In Two-Phase Concurrent Film Flow. AIChE J. 21, 308-318.

Jayanti, S., Hewitt, G.F., White, S.P., 1990. Time-dependent behaviour of the liquid film in horizontal annular flow. Int. J. Multiph. Flow 16, 1097-1116.

Jayanti, S., Rajesh Reddy, K., 2013. Effect of spacer grids on CHF in nuclear rod bundles. Nucl. Eng. Des. 261, 66-75.

Kamei, T., Serizawa, A., 1998. Measurement of 2-dimensional local instantaneous liquid film thickness around simulated nuclear fuel rod by ultrasonic transmission technique. Nucl. Eng. Des. 184, 349-362.

Kraemer, W., Proebstle, G., Uebelhack, W., Keheley, T., Tsuda, K., Kato, S., 1995. The ULTRAFLOW spacer - an advanced feature of ATRIUM fuel assemblies for boiling water reactors. Nucl. Eng. Des. $154,17-21$

Nishida, K., Kanazawa, T., Yokomizo, O., Masuhara, Y., 1994. Spacer Effect on Liquid Film Flow and Critical Power in BWR Fuel Bundles. J. Nucl. Sci. Technol. 31, 213-221.

Paras, S. V, Karabelas, A.J., Engineering, C.P., 1991. Properties of the liquid layer in horizontal annular flow. Int. J. Multiph. Flow 17, 439-454.

Pham, S.H., Kawara, Z., Yokomine, T., Kunugi, T., 2014. Detailed observations of wavy interface behaviors of annular two-phase flow on rod bundle geometry. Int. J. Multiph. Flow 59, 135-144.

Renksizbulut, M., Hadaller, G.I., 1986. Experimental study of turbulent flow through a square-arry rod bundle 91, 41-55. 
Schubring, D., Ashwood, A.C., Shedd, T. a., Hurlburt, E.T., 2010a. Planar laser-induced fluorescence (PLIF) measurements of liquid film thickness in annular flow. Part I: Method and data. Int. J. Multiph. Flow 36, 815-824.

Schubring, D., Shedd, T. a., Hurlburt, E.T., 2010b. Studying disturbance waves in vertical annular flow with high-speed video. Int. J. Multiph. Flow 36, 385-396.

Shin, B.S., Chang, S.H., 2009. CHF experiment and CFD analysis in a $2 \times 3$ rod bundle with mixing vane. Nucl. Eng. Des. 239, 899-912.

Yano, T., Aritomi, M., Kikura, H., Obata, H., 2001a. Mechanistic modeling for ring-type boiling water reactor fuel spacer design (3) run-off effect and model formulation. Nucl. Eng. Des. 210, 21-36.

Yano, T., Aritomi, M., Kikura, H., Obata, H., 2001b. Mechanistic modeling for ring-type BWR fuel spacer design 2. Local pressure drop and narrow channel effect. Nucl. Eng. Des. 205, 295-303.

Yano, T., Kodama, E., Aritomi, M., 2000. Mechanistic modeling for ring-type BWR fuel spacer design 1 . Drift flow model. Nucl. Eng. Des. 201, 177-188.

Zhao, Y., Markides, C.N., Matar, O.K., Hewitt, G.F., 2013. Disturbance wave development in two-phase gas-liq uid upwards vertical annular flow. Int. J. Multiph. Flow 55, 111-129.

\section{Figure Captions}

Fig. 1. Schematic diagram of experimental apparatus

Fig. 2. (a) Test-section's horizontal cross-section and backlight arrangement; (b) inlet structure's vertical cross-section; and (c) technical specifications of spacer.

Fig. 3. (a) Image distortion problem and (b) an attempt to keep liquid from flowing across the image window.

Fig. 4. Experimental arrangement for close-up visualization near spacer.

Fig. 5. (a) Image processing procedure used in liquid film measurement and (b) example result with images captured at $10 \mathrm{~cm}$ with $j_{G}=22.7 \mathrm{~m} / \mathrm{s}$ and $j_{L}=0.032 \mathrm{~m} / \mathrm{s}$.

Fig. 6. Normalized cross-correlation function (CCF) of time-resolved thickness series at $5^{\text {th }}$ and $57^{\text {th }}$ pixelrow of image. The data were obtained on the corner rod at position $-6 \mathrm{~cm}$ with $j_{G}=44.5 \mathrm{~m} / \mathrm{s}$ and $j_{L}=0.02 \mathrm{~m} / \mathrm{s}$. 
Fig. 7. Image processing procedure used in droplets' measurement. The image was captured at $42 \mathrm{~cm}$ with $j_{G}=62.2 \mathrm{~m} / \mathrm{s}$ and $j_{L}=0.025 \mathrm{~m} / \mathrm{s}$.

Fig. 8. Example thickness signals of disturbance waves obtained at $-6 \mathrm{~cm}$ on the corner rod with $j_{L}=$ $0.032 \mathrm{~m} / \mathrm{s}$.

Fig. 9. Mean liquid film thickness.

Fig. 10. Probability density of liquid film thickness.

Fig. 11. Root mean square (RMS) of liquid-film thickness fluctuations.

Fig. 12. Power spectral density (PSD) of liquid film thickness obtained at $-6 \mathrm{~cm}$ on corner rod.

Fig. 13. PSD of liquid film thickness obtained with $j_{L}=0.025 \mathrm{~m} / \mathrm{s}$.

Fig. 14. Mean wave velocity.

Fig. 15. Size distribution of liquid droplets.

Fig. 16. Spatial distribution of liquid droplets (Data for $j_{G}=62.2 \mathrm{~m} / \mathrm{s}$ at $-6 \mathrm{~cm}$ are not available).

Fig. 17. Probability density of droplet velocity.

Fig. 18. Mean droplet velocity by diameter.

Fig. 19. Images taken right up- and downstream of the second spacer when all water lines were turned off.

Fig. 20. Large-amplitude waves entering the spacer region.

Fig. 21. Generation of liquid droplets at the top of the spacer structure.

Fig. 22. Droplet behaviors at regions right up- and downstreams of the spacer. Image data are captured with $j_{G}=44.5 \mathrm{~m} / \mathrm{s}$ and $j_{L \times 3}=0.032 \mathrm{~m} / \mathrm{s}$. 
Fig. 1. Schematic diagram of experimental apparatus

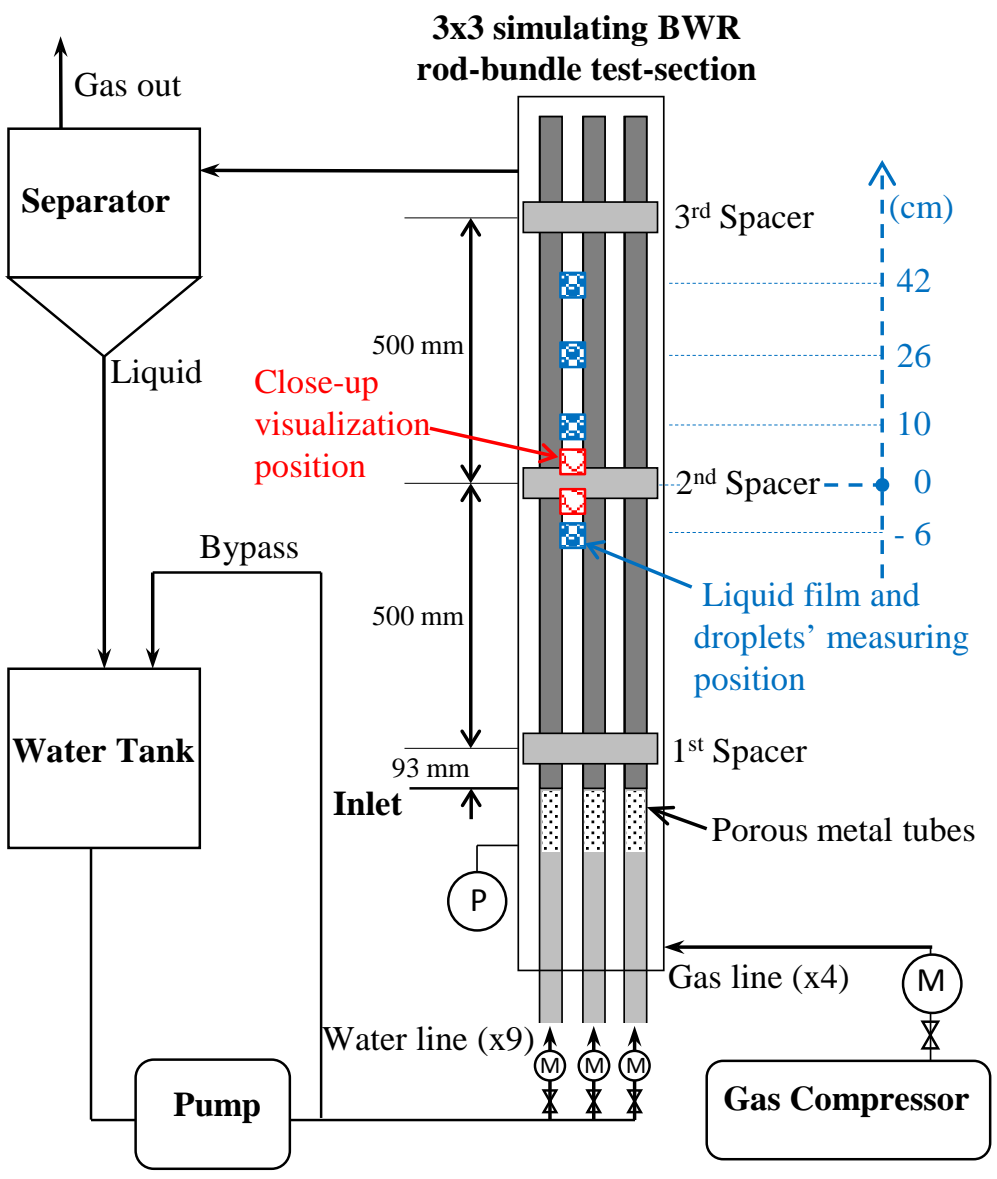


Fig. 2. (a) Test-section's horizontal cross-section and backlight arrangement; (b) inlet structure's vertical cross-section; and (c) technical specifications of spacer.

(a)

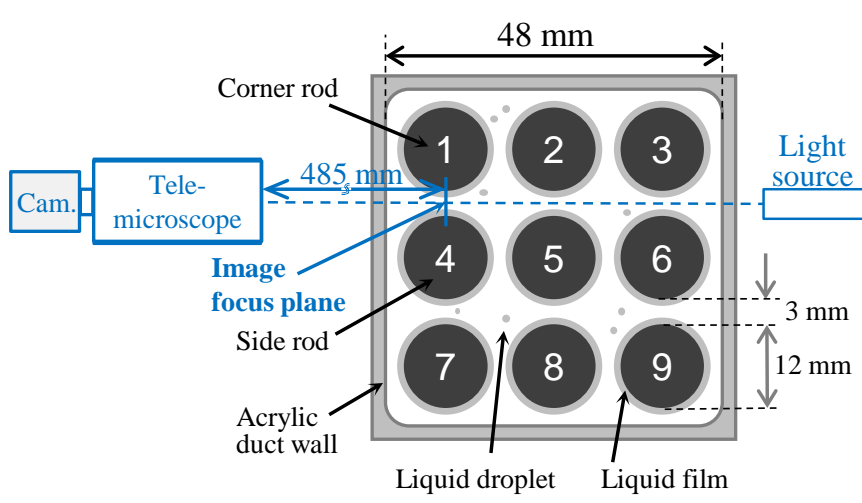

(b)

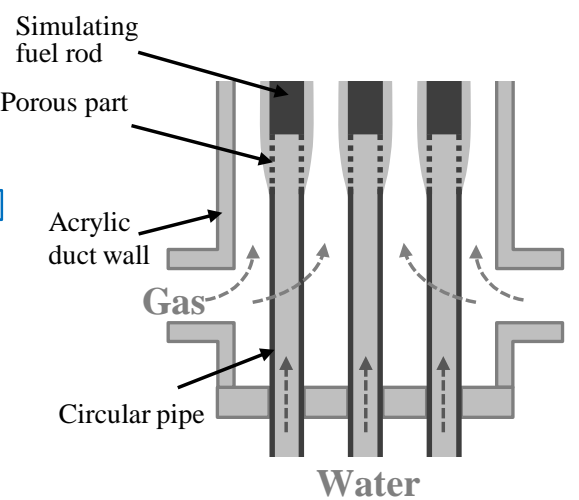

(c)

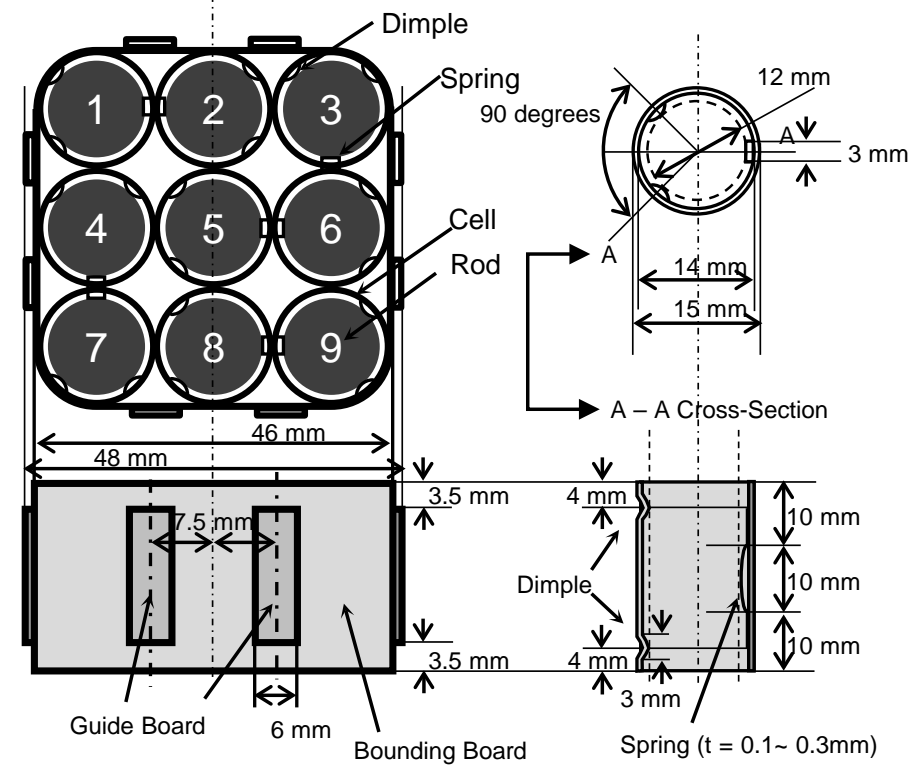

Circular ferrule-type spacer

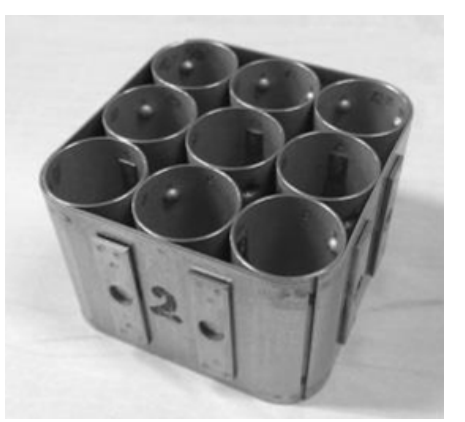


Fig. 3. (a) Image distortion problem and (b) an attempt to keep liquid from flowing across the image window.

(a)

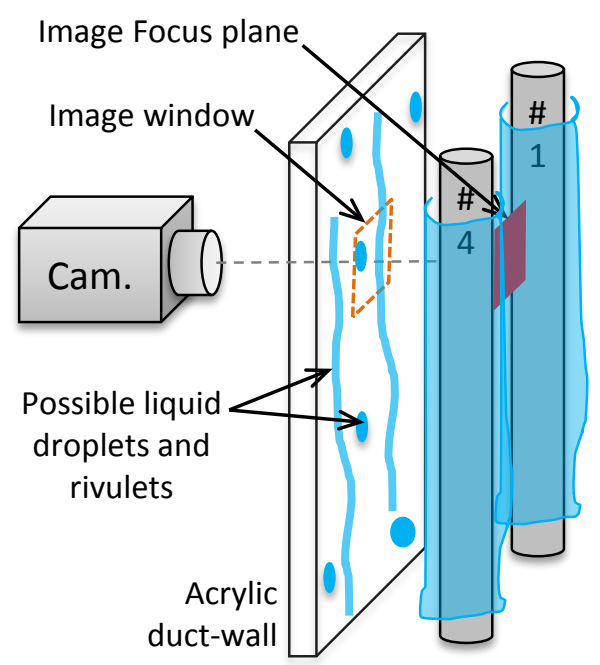

(b)

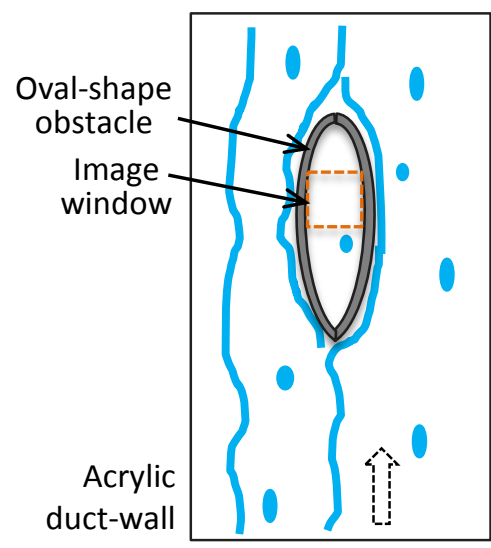


Fig. 4. Experimental arrangement for close-up visualization near spacer.

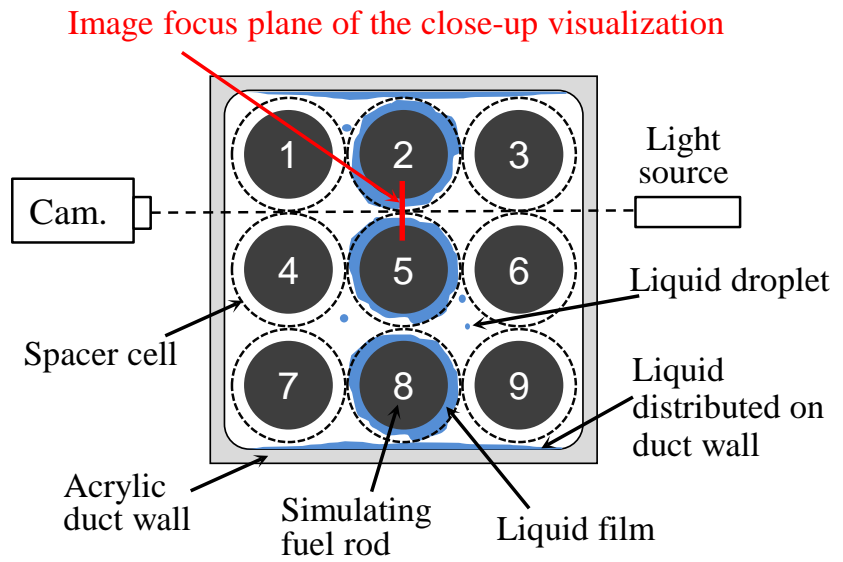


Fig. 5. (a) Image processing procedure used in liquid film measurement and (b) example result with images captured at $10 \mathrm{~cm}$ with $j_{G}=22.7 \mathrm{~m} / \mathrm{s}$ and $j_{L}=0.032 \mathrm{~m} / \mathrm{s}$.

(a)

(0) Original image

(1) Edges detected by Canny operator (both weak and strong)

(2) Edges not belonging to the droplets (subtract droplet' edges)

(3) Strongest edge of each side is selected based on intensity gradient

(4) Edge points located at the middle row of the image

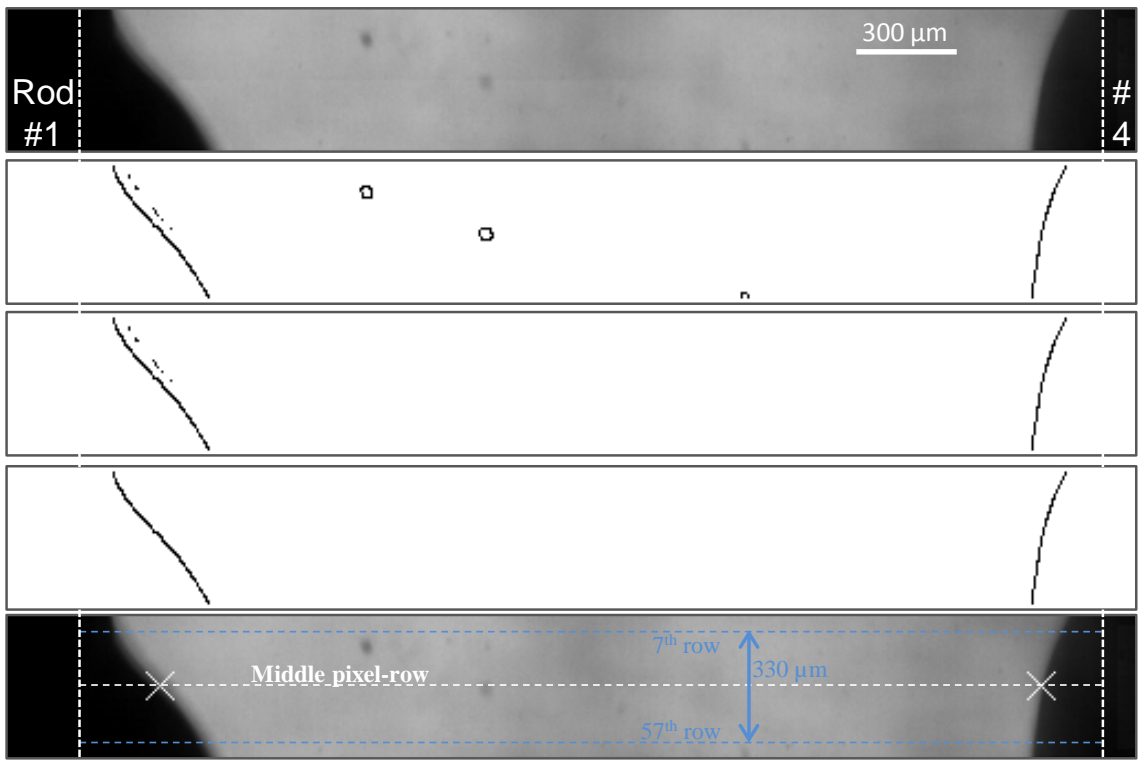

(b)

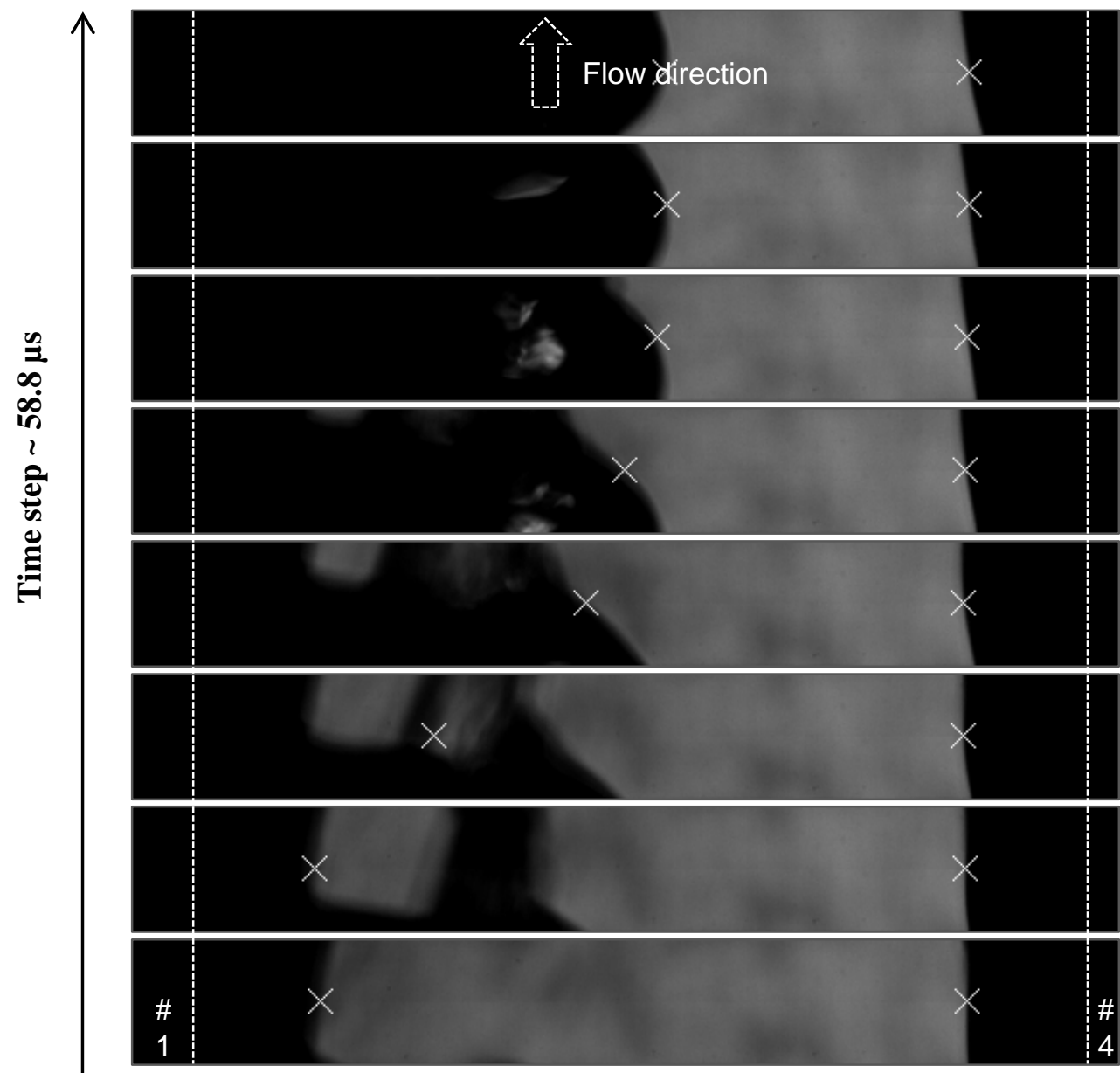


Fig. 6. Normalized cross-correlation function (CCF) of time-resolved thickness series at $5^{\text {th }}$ and $57^{\text {th }}$ pixel-row of image. The data were obtained on the corner rod at position -6 $\mathrm{cm}$ with $j_{G}=44.5 \mathrm{~m} / \mathrm{s}$ and $j_{L}=0.02 \mathrm{~m} / \mathrm{s}$.

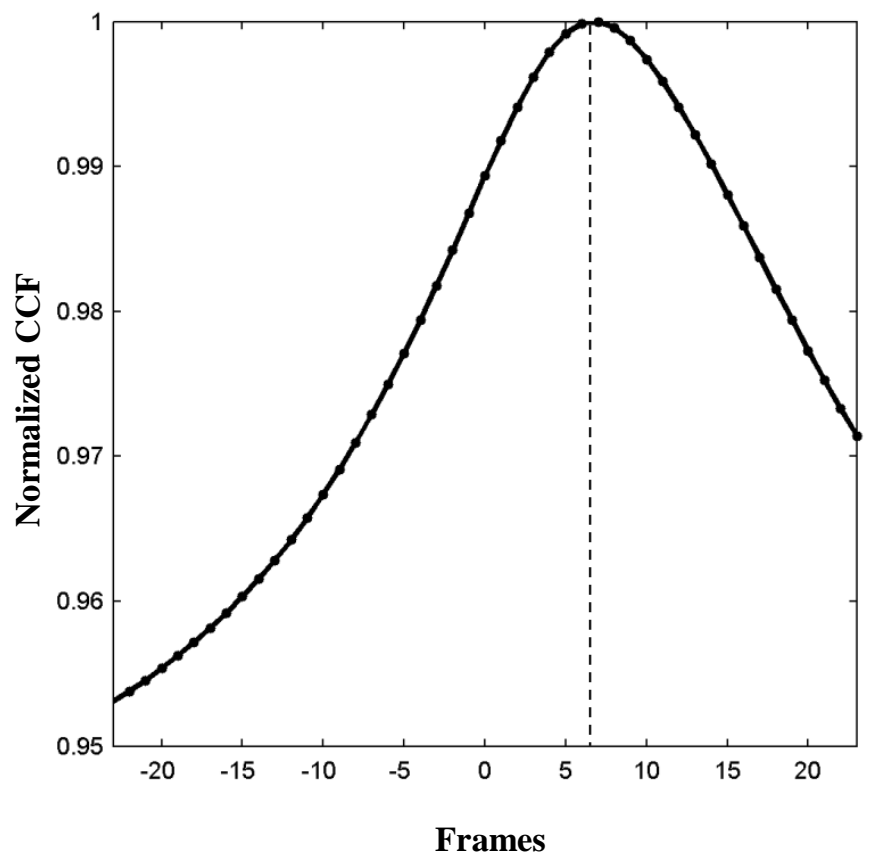


Fig. 7. Image processing procedure used in droplets' measurement. The image was captured at $42 \mathrm{~cm}$ with $j_{G}=62.2 \mathrm{~m} / \mathrm{s}$ and $j_{L}=0.025 \mathrm{~m} / \mathrm{s}$.

(0) Original image $512 \times 512$ pixels

(3) Removes single-open lines

(4) Results displayed by equivalent diameters $\left(d_{e}\right)$
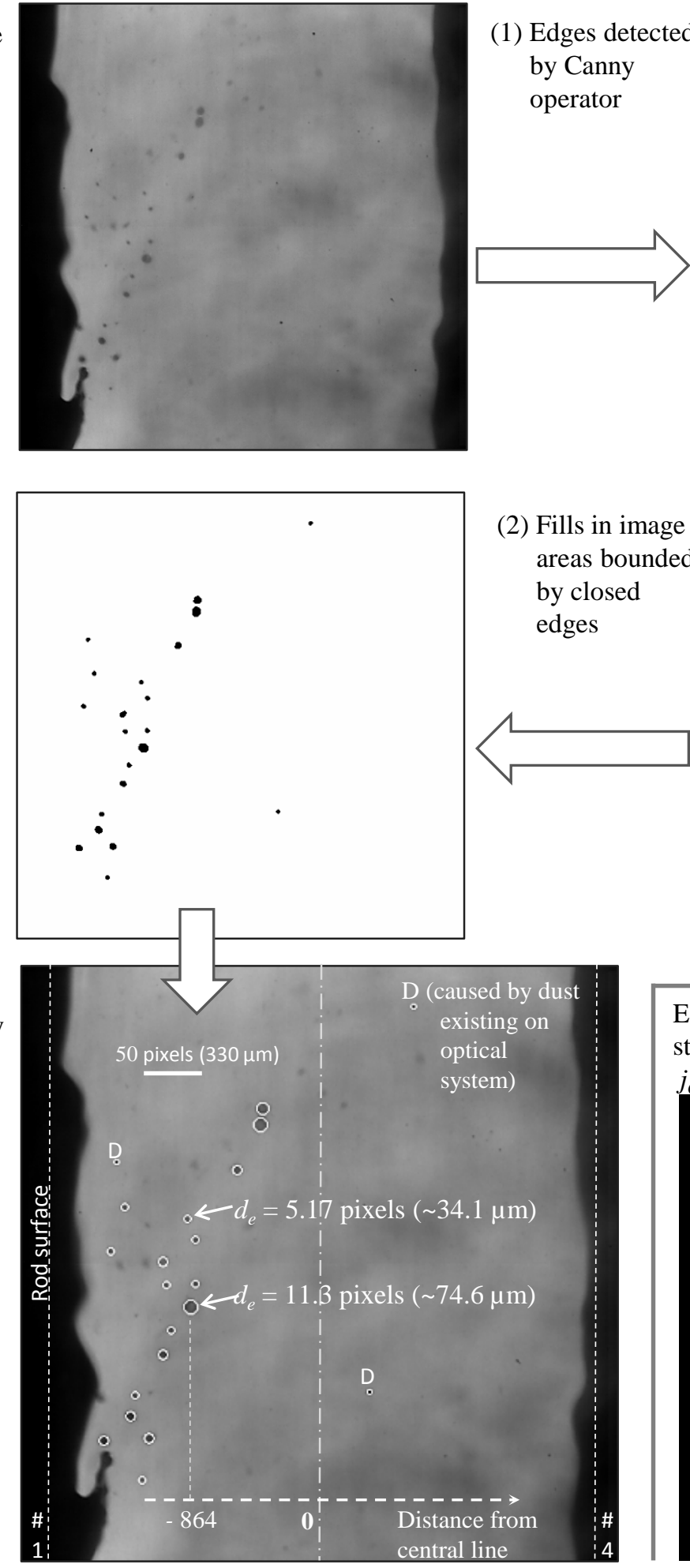

Example of droplets detection with quite strong noises (at $10 \mathrm{~cm} ; j_{L}=0.032$ and $j_{G}=22.7 \mathrm{~m} / \mathrm{s}$ )

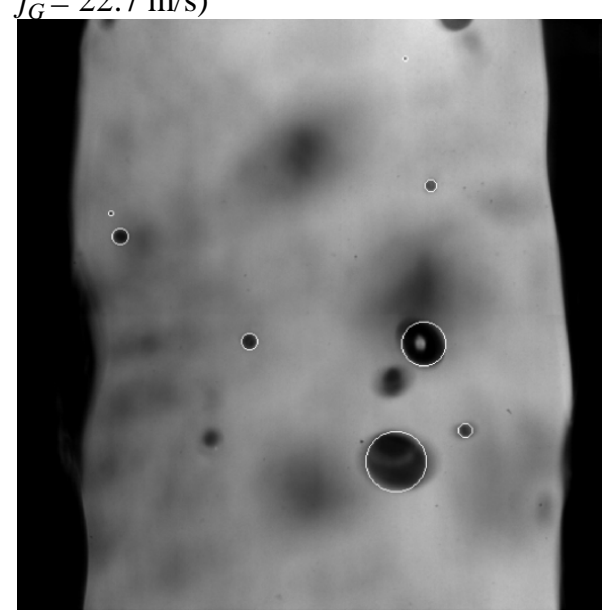


Fig. 8. Example thickness signals of disturbance waves obtained at $-6 \mathrm{~cm}$ on the corner rod with $j_{L}=0.032 \mathrm{~m} / \mathrm{s}$.
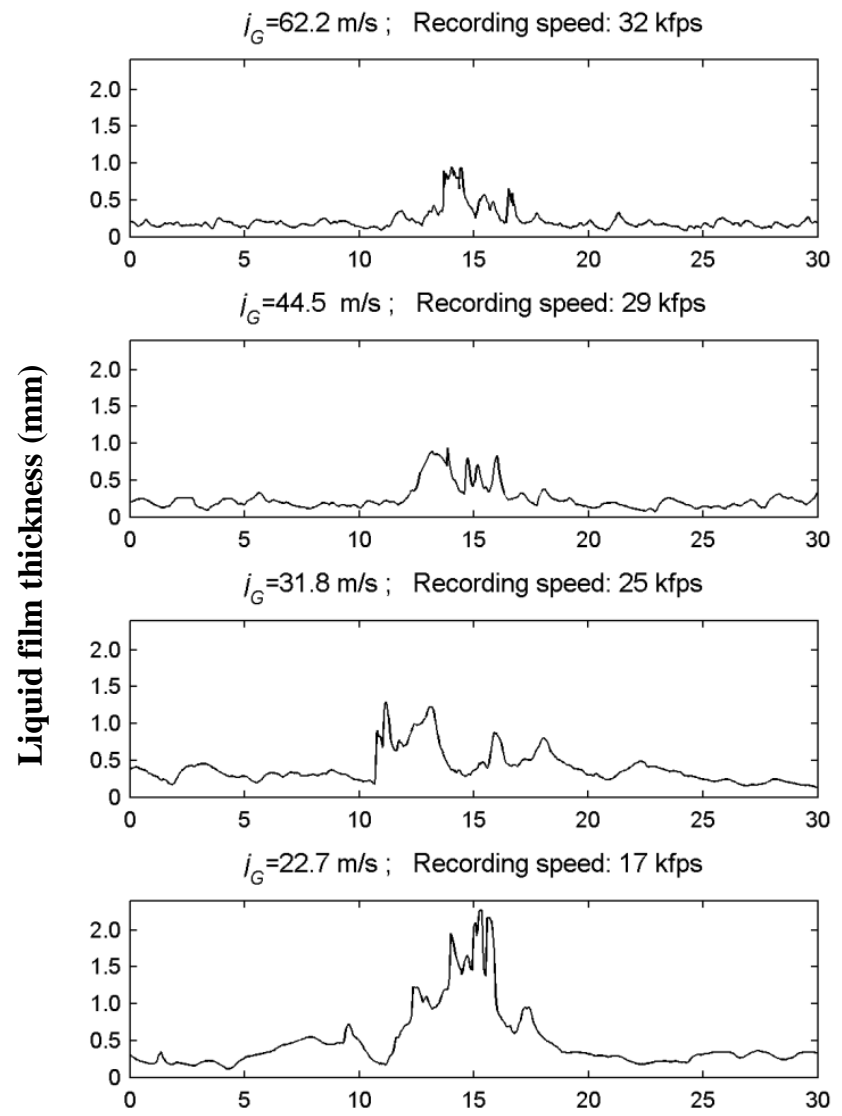

Time (ms) 


\section{Fig. 9. Mean liquid film thickness.}

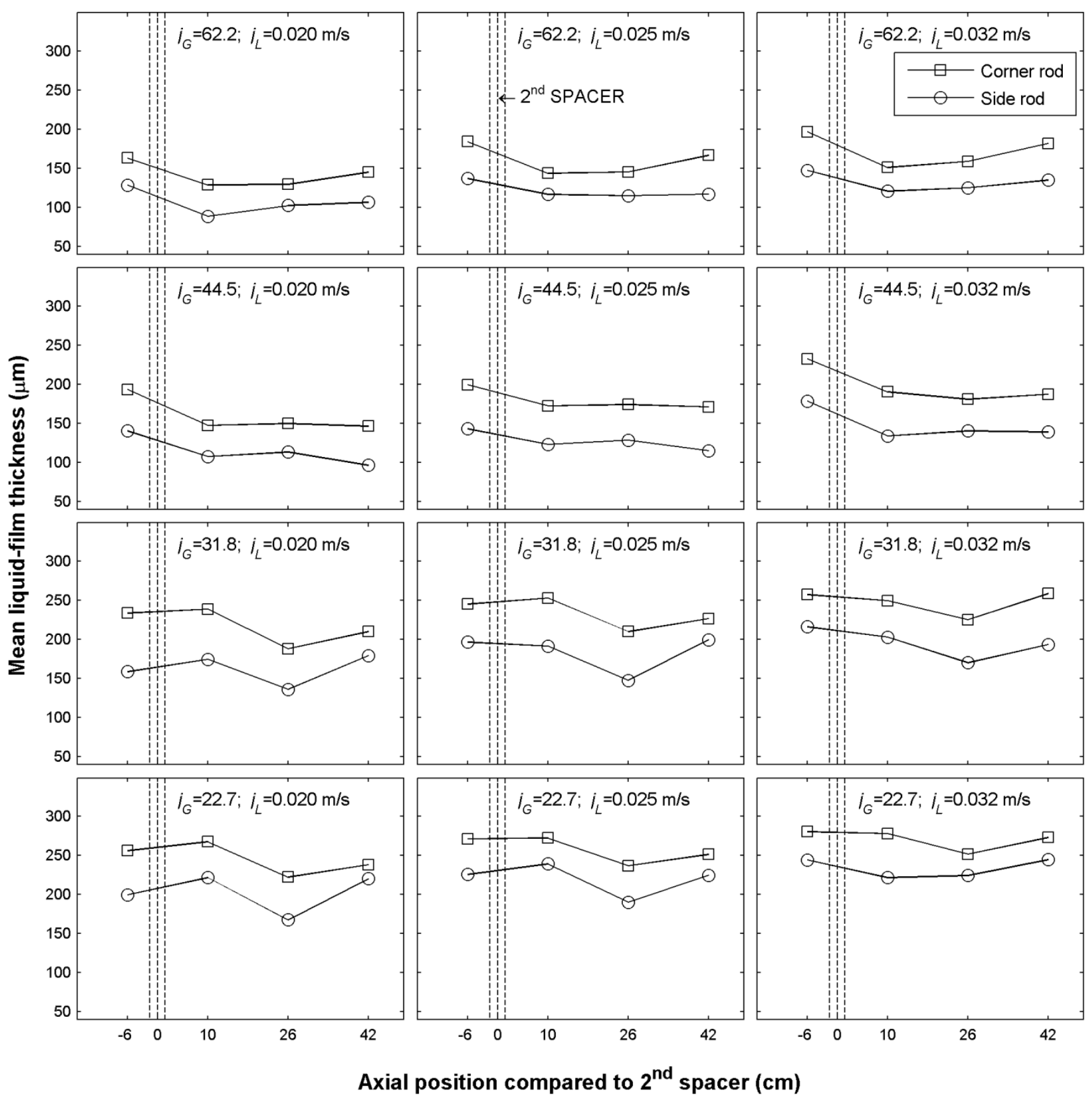


Fig. 10. Probability density of liquid film thickness.
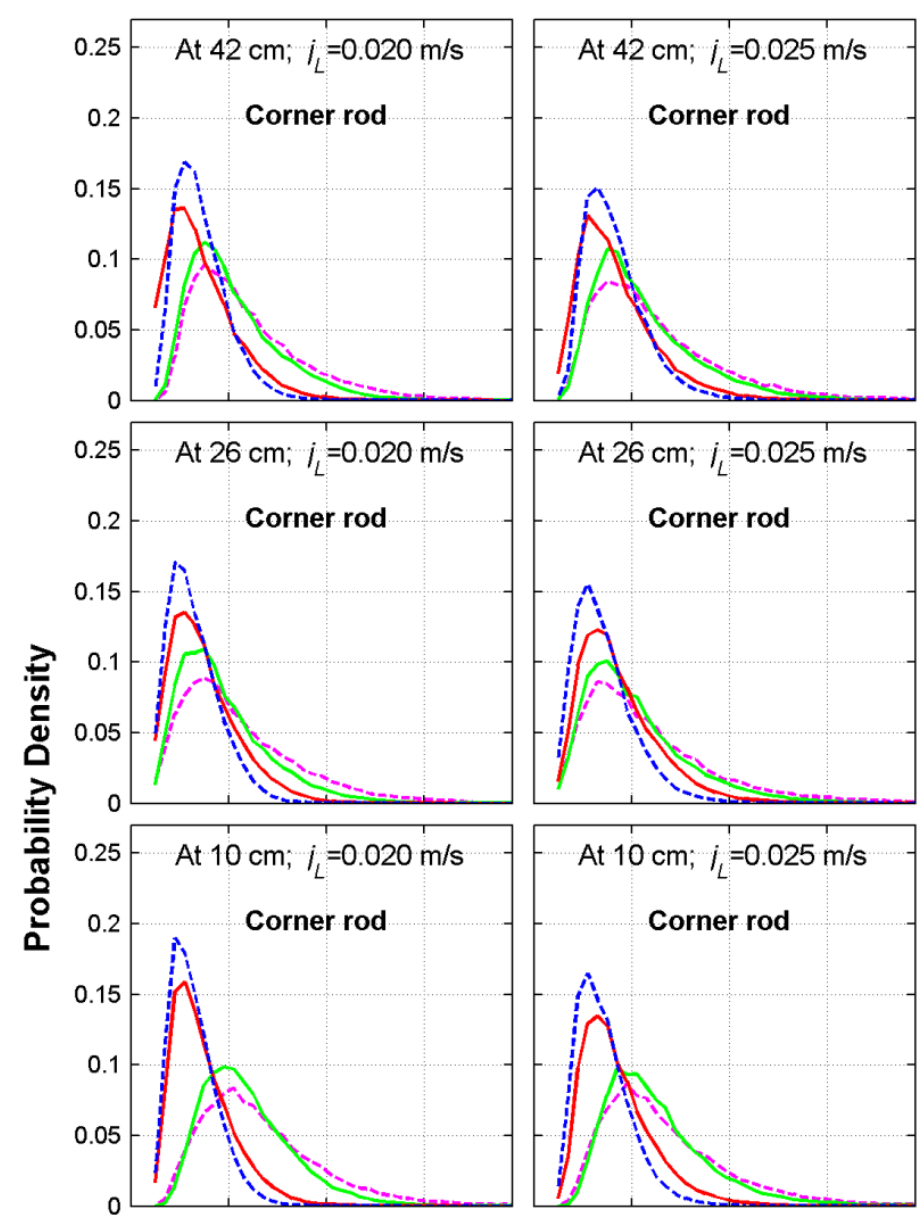

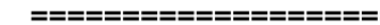

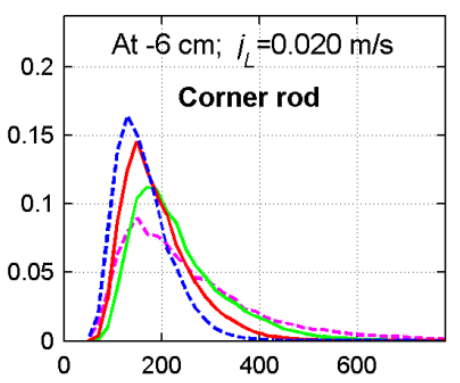

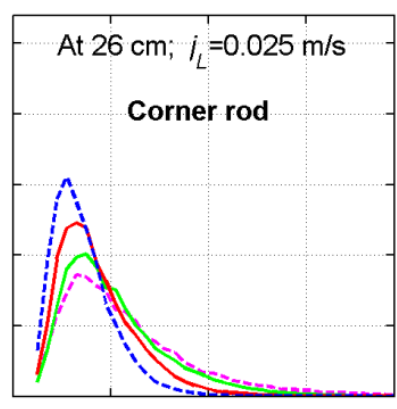
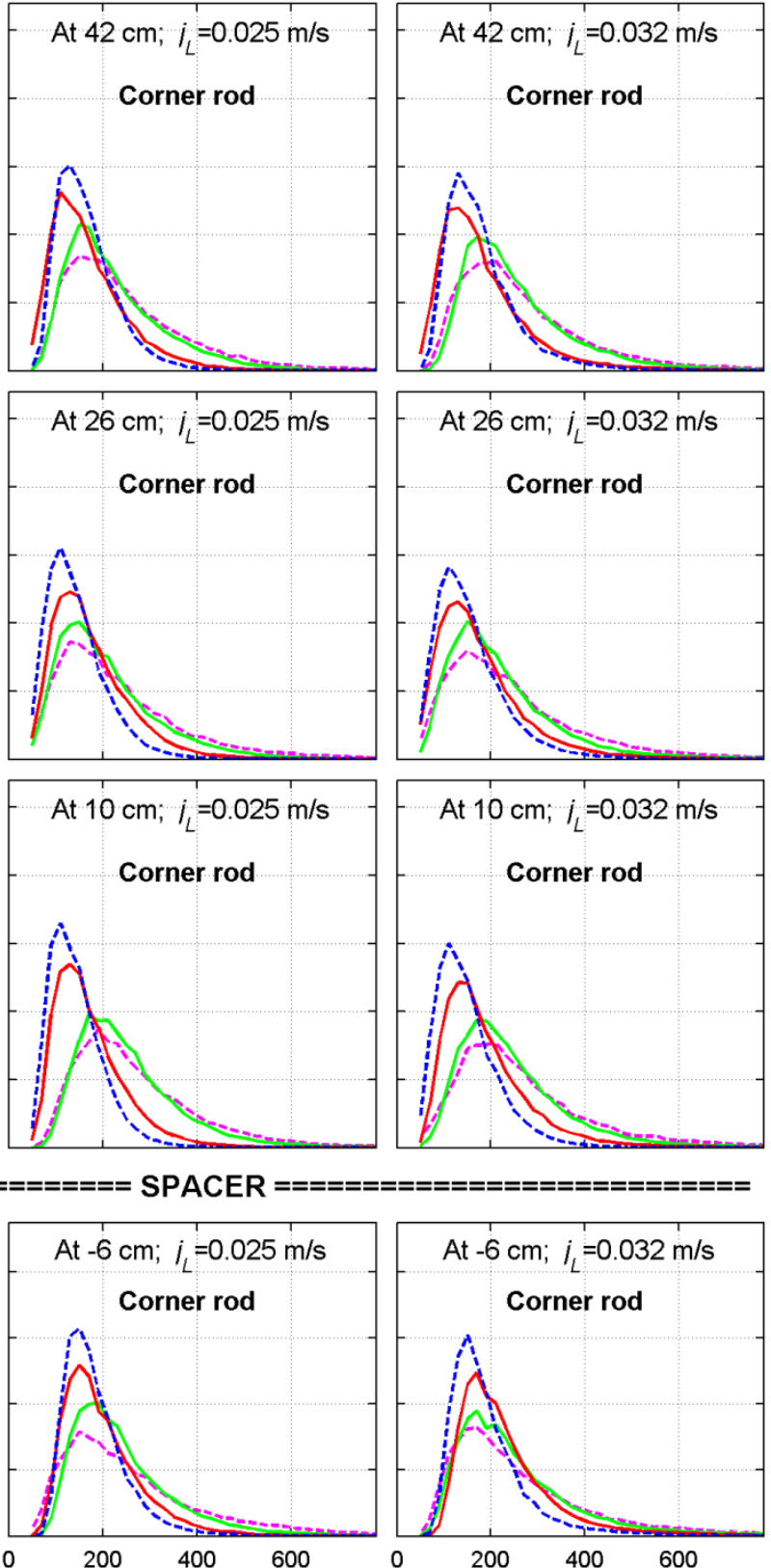
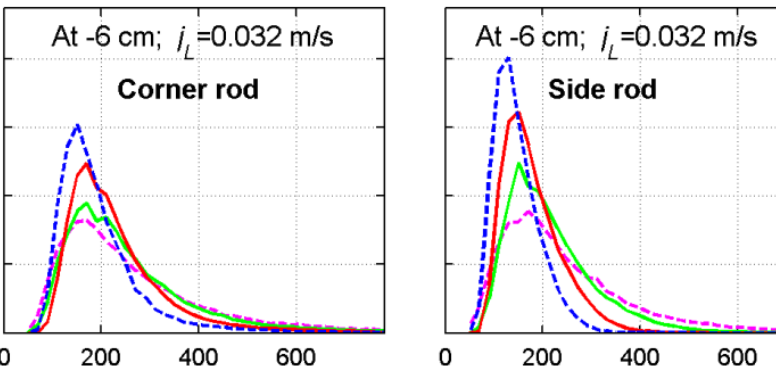

Liquid film thickness $(\mu \mathrm{m})$ 
Fig. 11. Root mean square (RMS) of liquid-film thickness fluctuations.

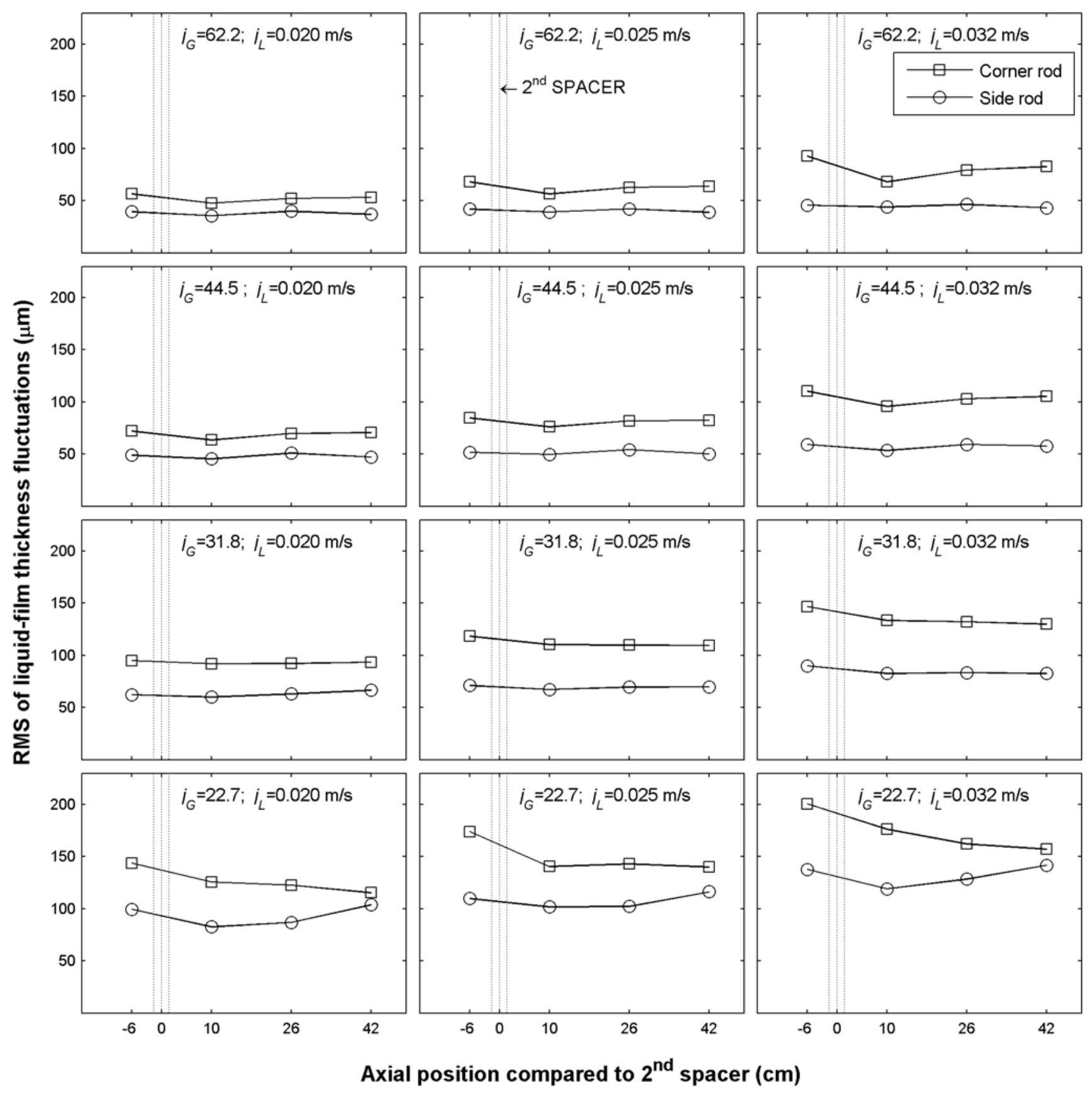


Fig. 12. Power spectral density (PSD) of liquid film thickness obtained at $-6 \mathrm{~cm}$ on corner rod.

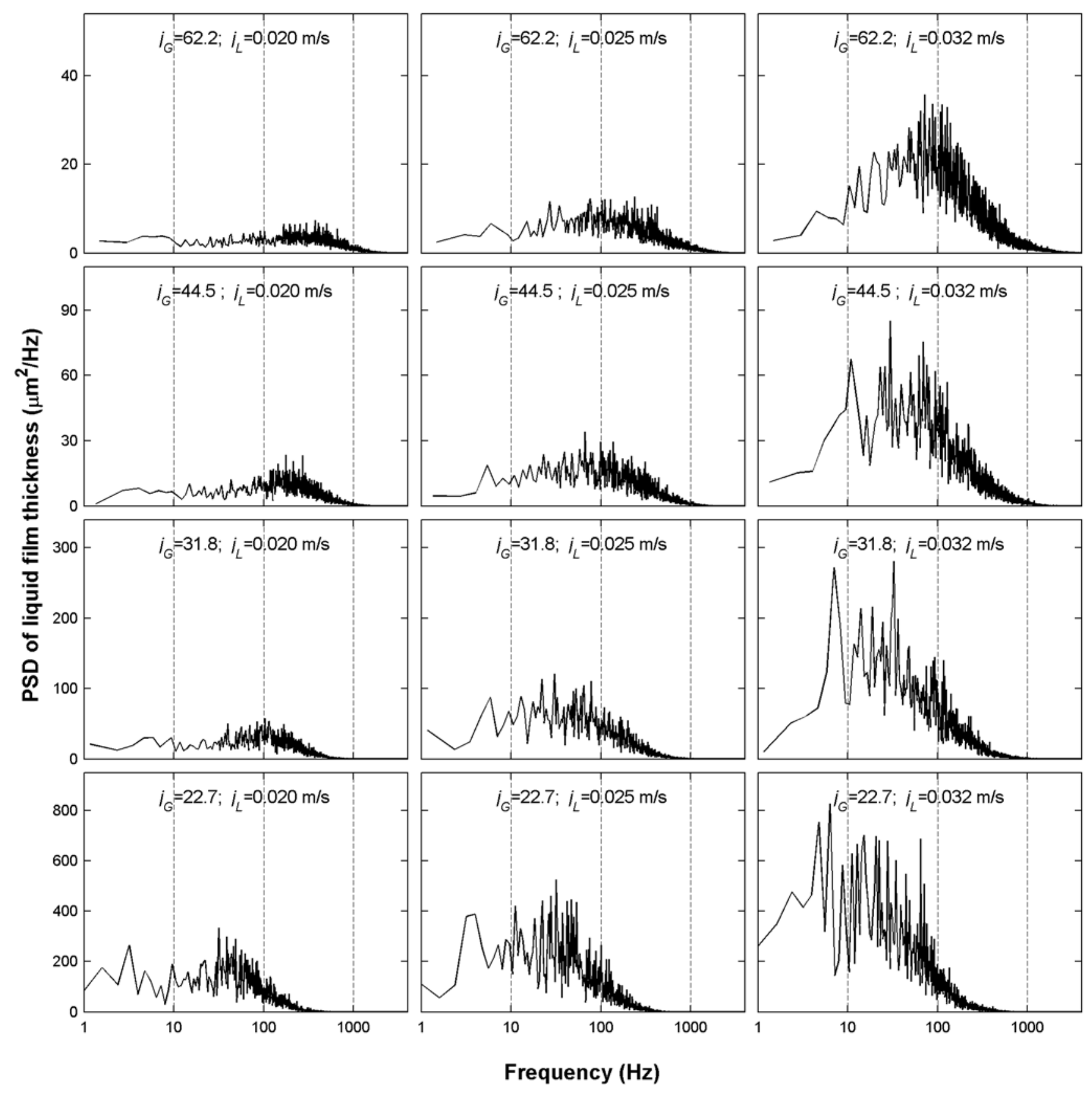


Fig. 13. PSD of liquid film thickness obtained with $j_{L}=0.025 \mathrm{~m} / \mathrm{s}$.
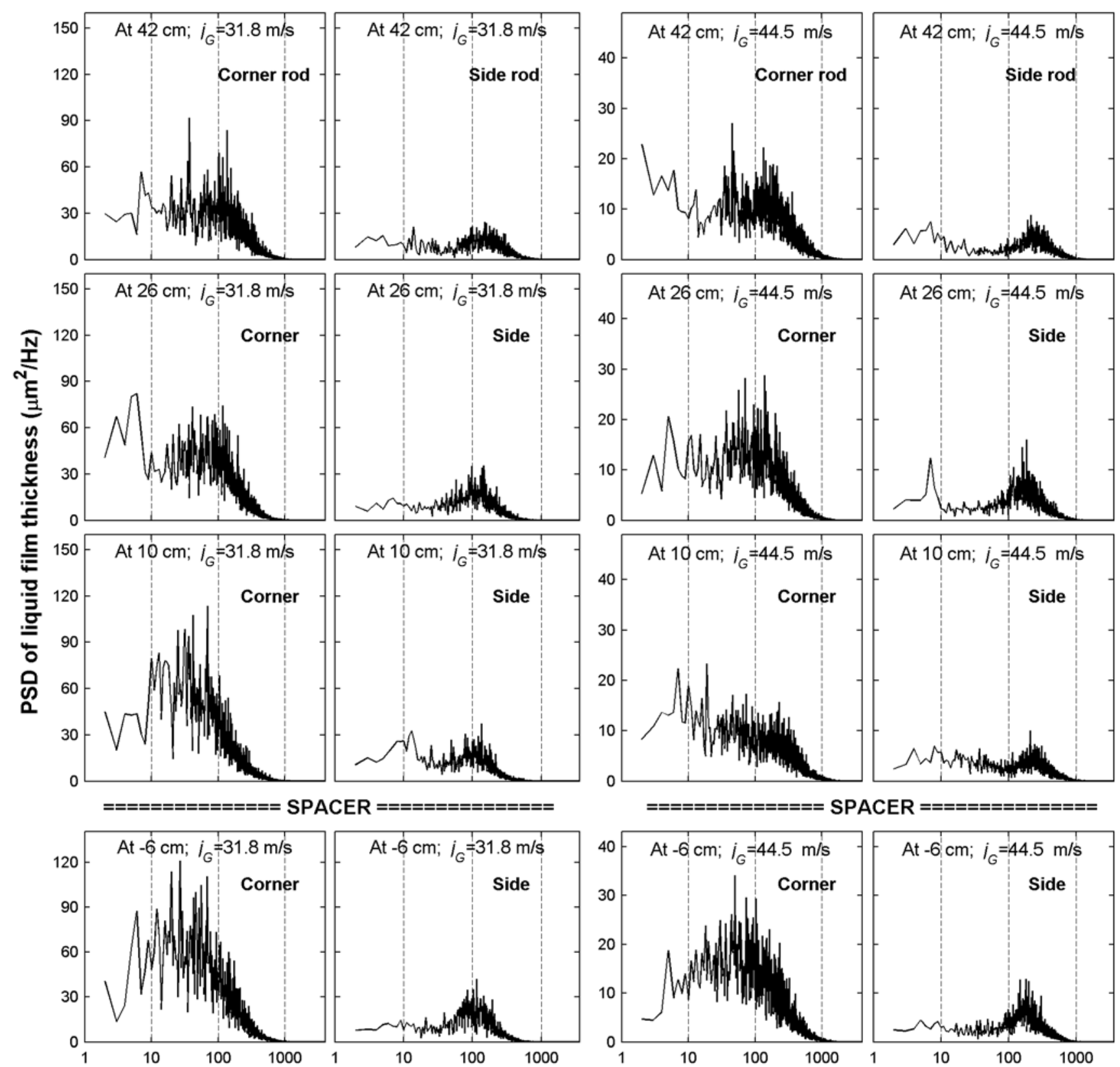

Frequency $(\mathrm{Hz})$ 
Fig. 14. Mean wave velocity.

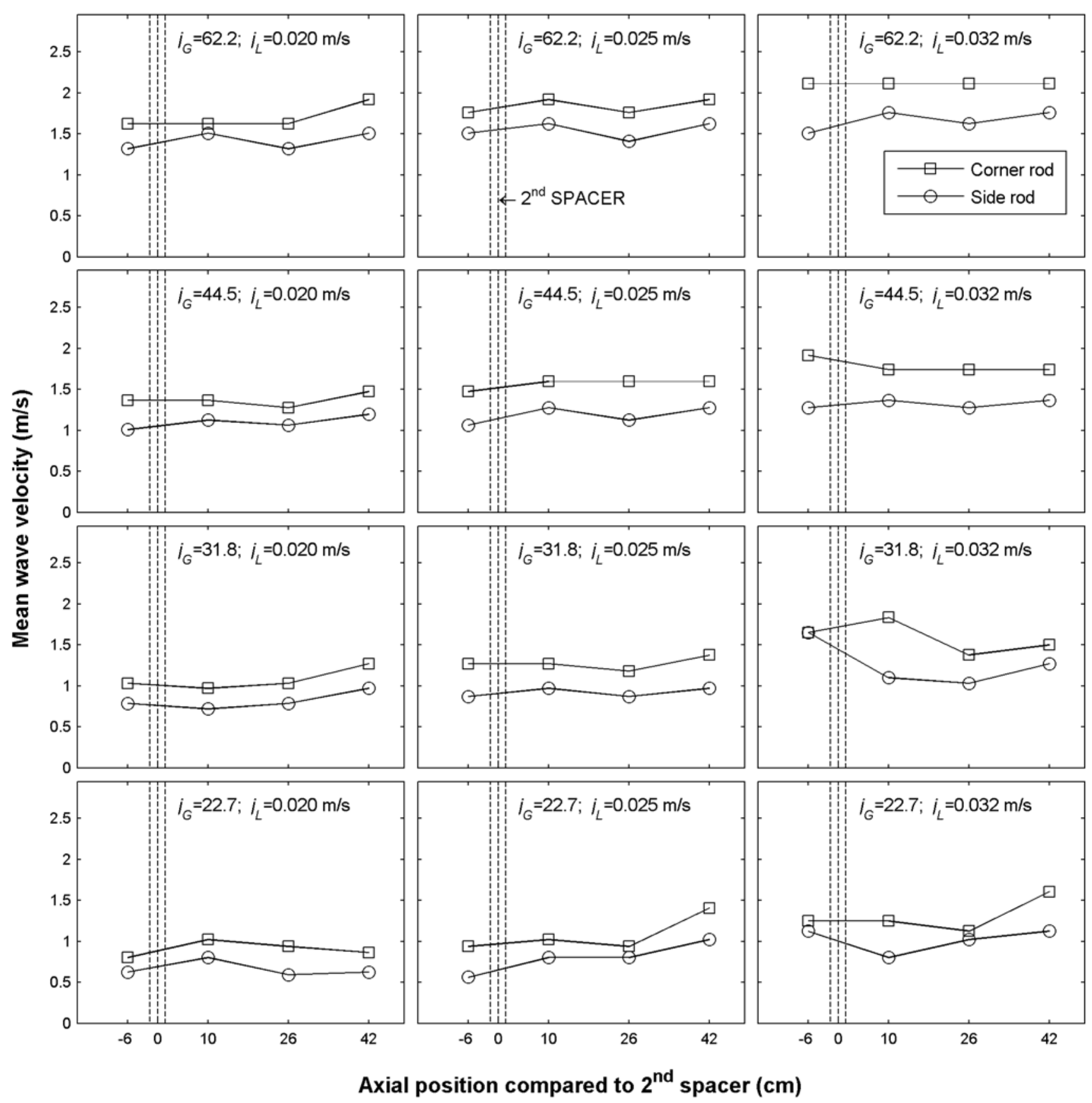


Fig. 15. Size distribution of liquid droplets.

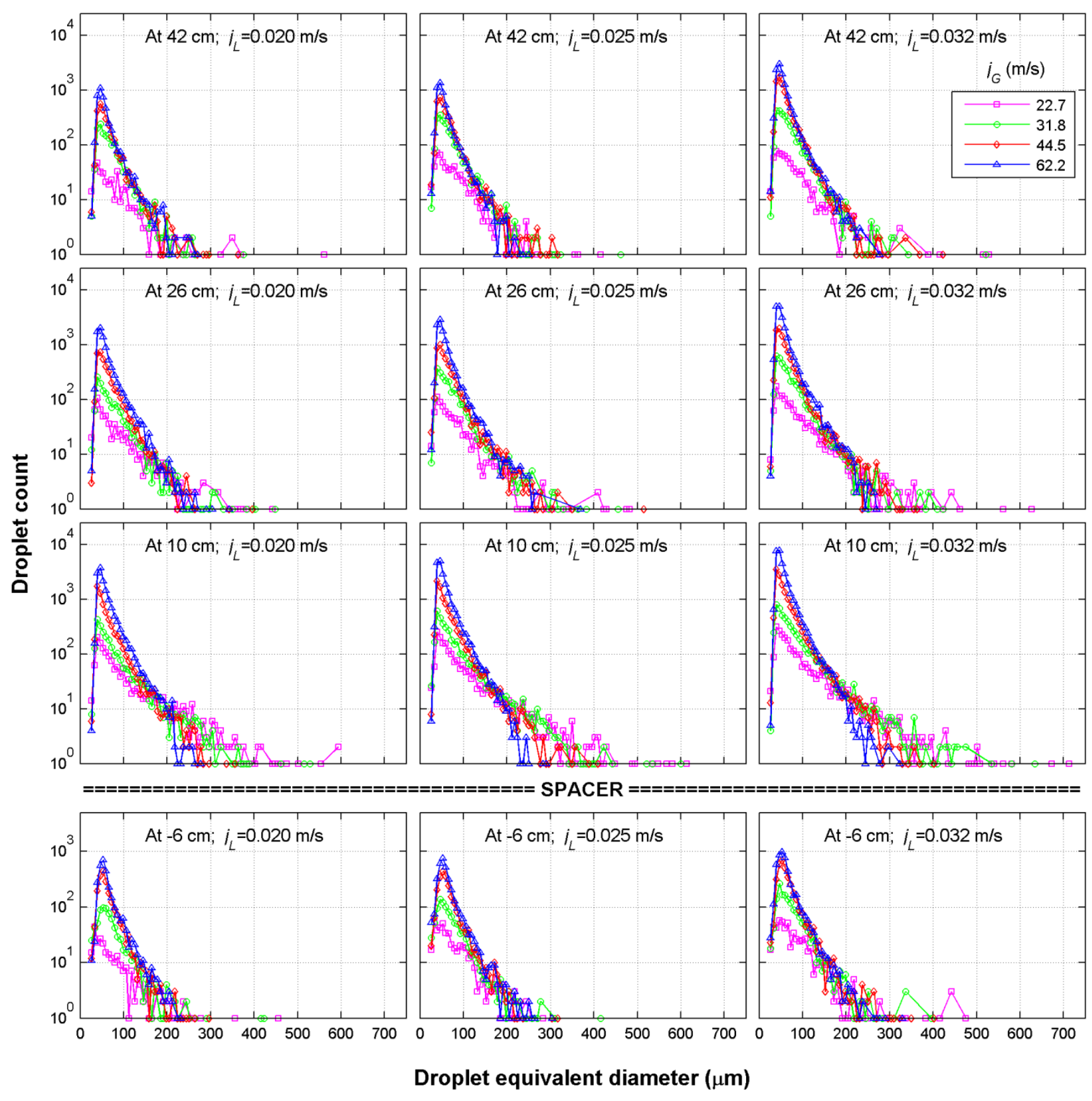


Fig. 16. Spatial distribution of liquid droplets (Data for $j_{G}=62.2 \mathrm{~m} / \mathrm{s}$ at $-6 \mathrm{~cm}$ are not available).
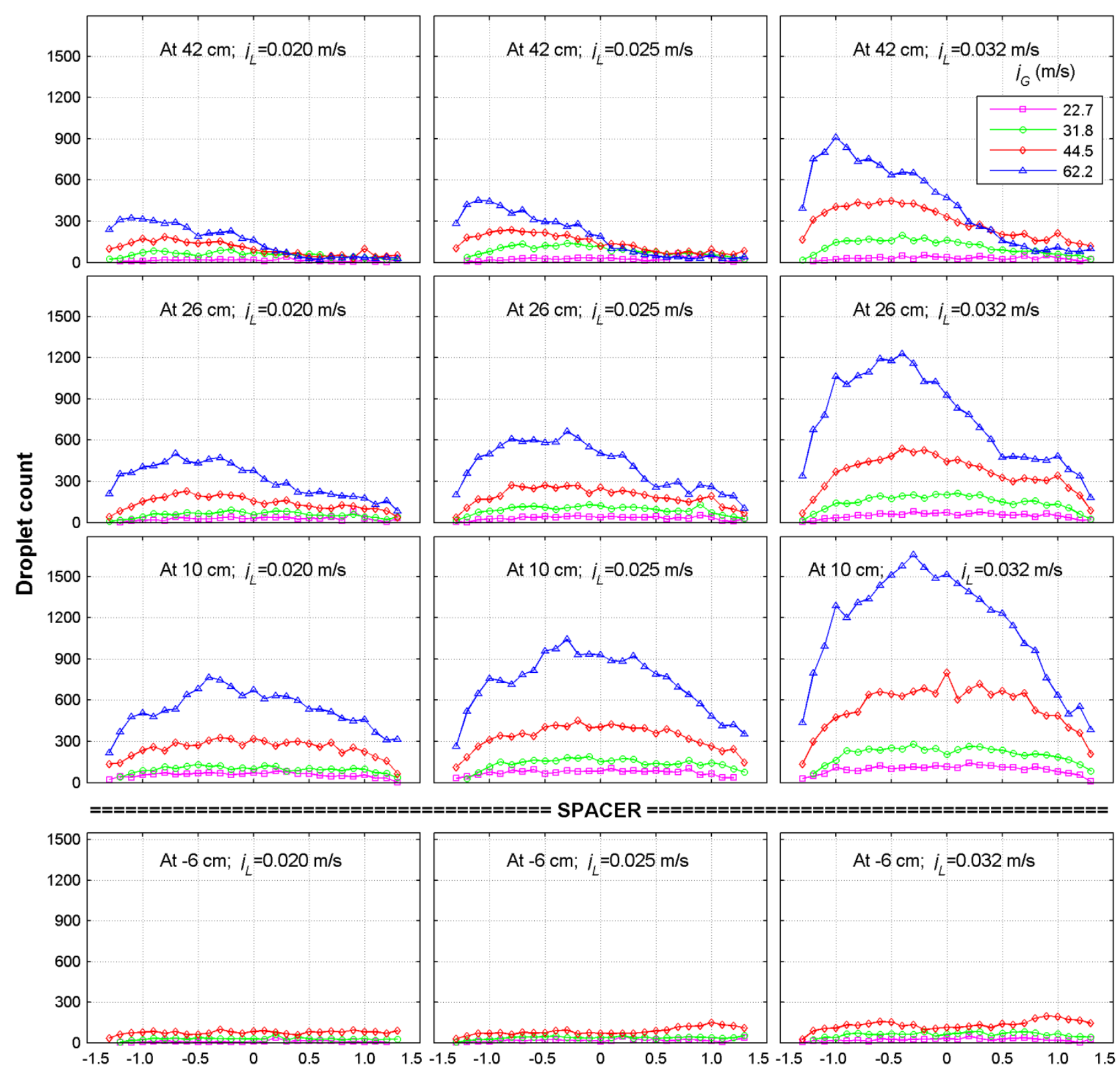

Distance from the center line of the gap $(\mathrm{mm})$ 
Fig. 17. Probability density of droplet velocity.
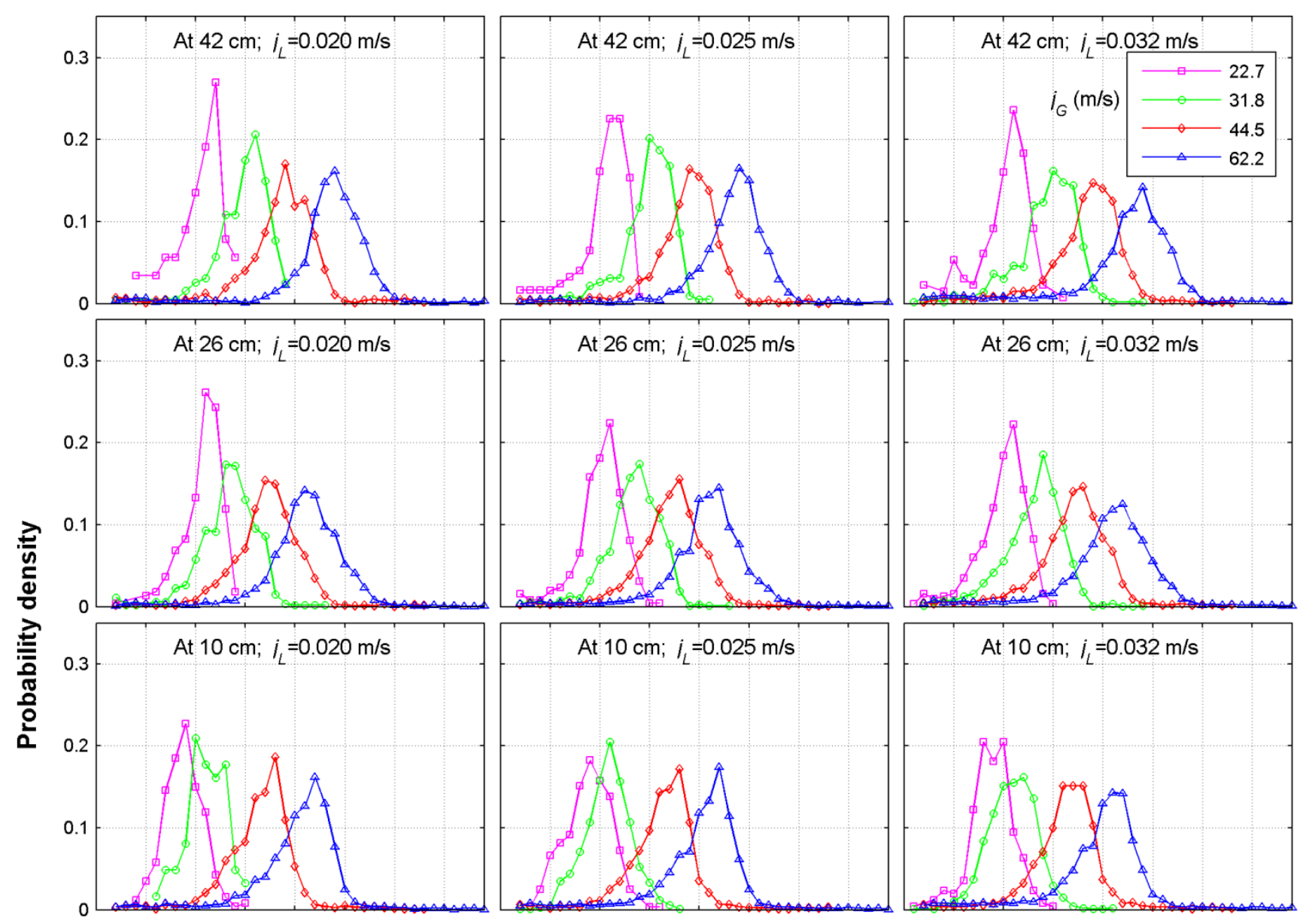

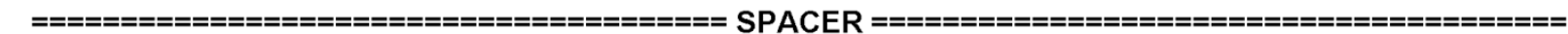
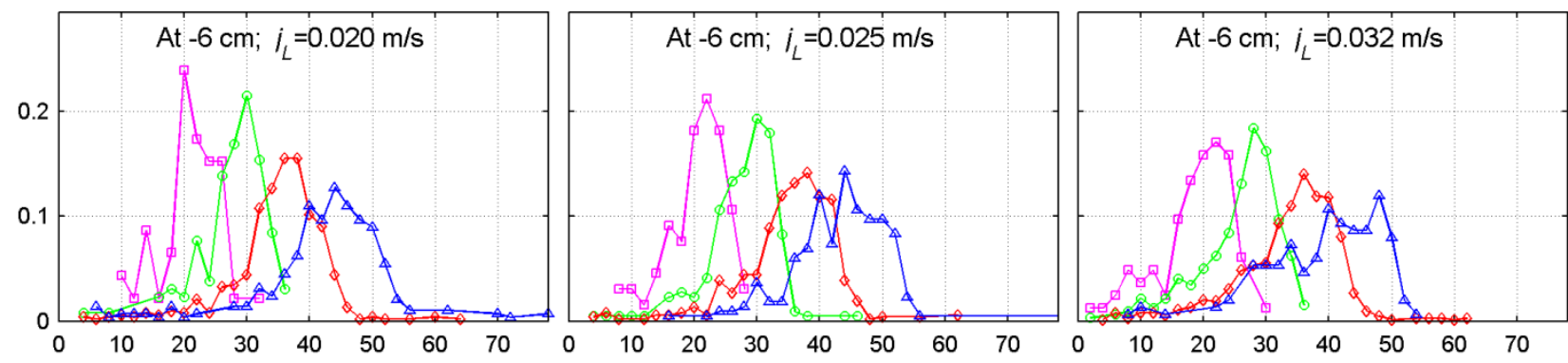

Droplet velocity $(\mathrm{m} / \mathrm{s})$ 
Fig. 18. Mean droplet velocity by diameter.

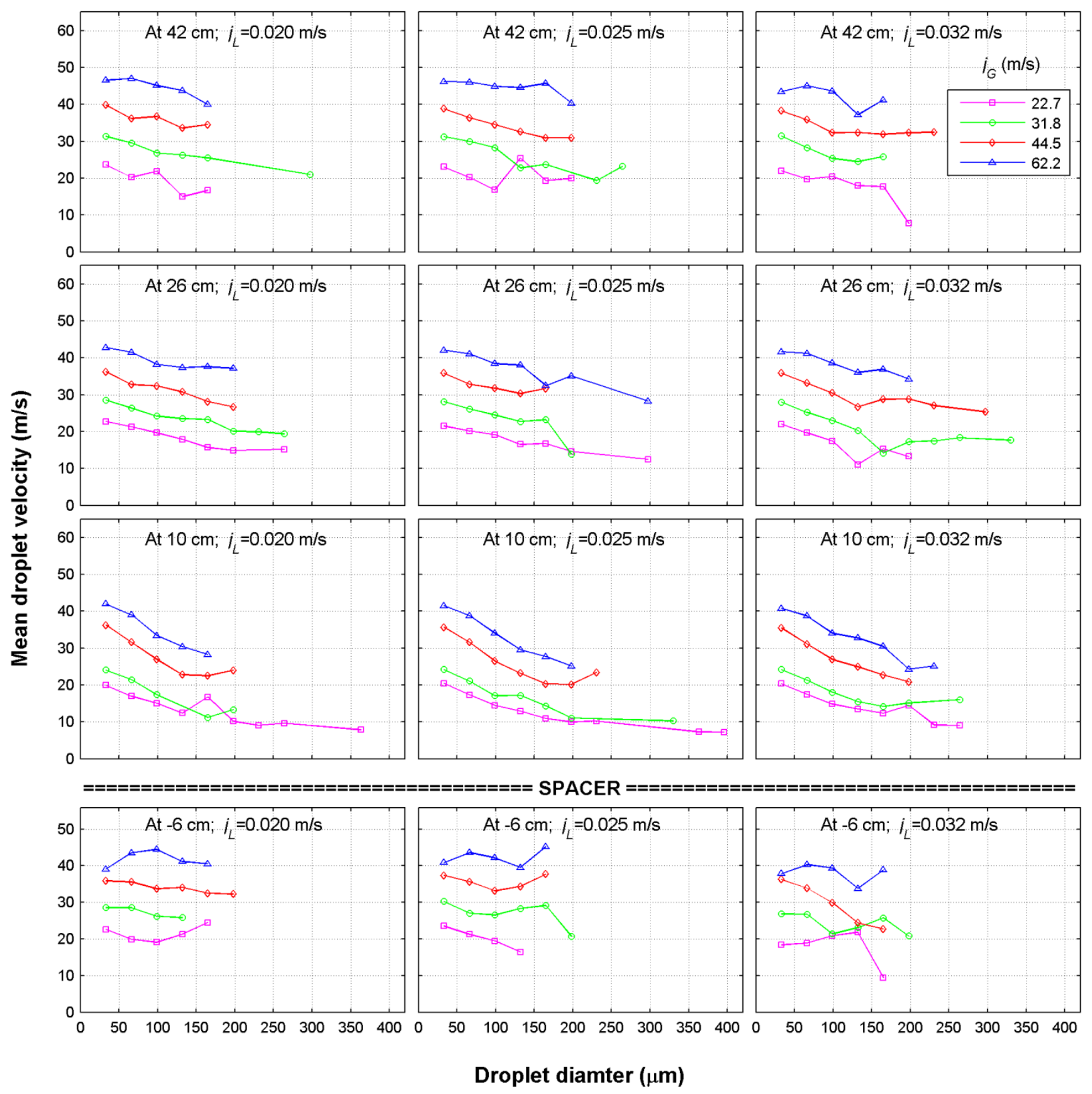


Fig. 19. Images taken right up- and downstream of the second spacer when all water lines were turned off.
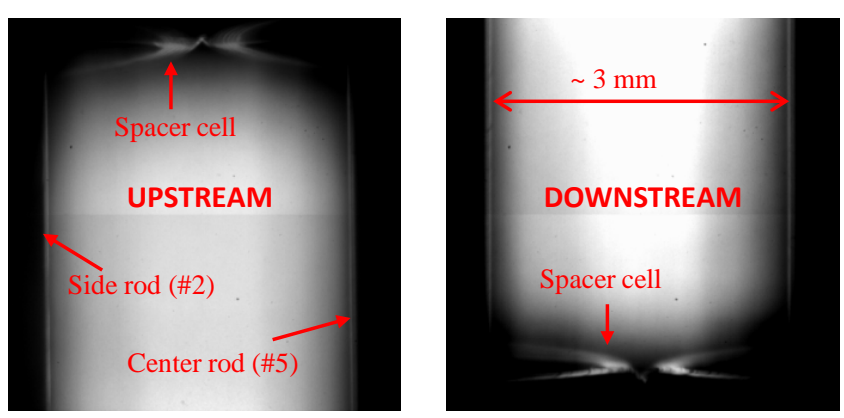
Fig. 20. Large-amplitude waves entering the spacer region.

(a) $j_{G}=31.8 ; j_{L \times 3}=0.032 \mathrm{~m} / \mathrm{s}$
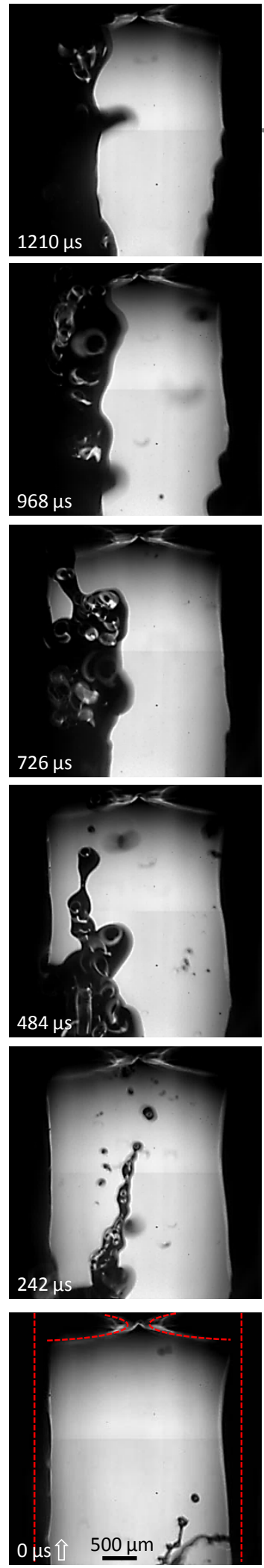
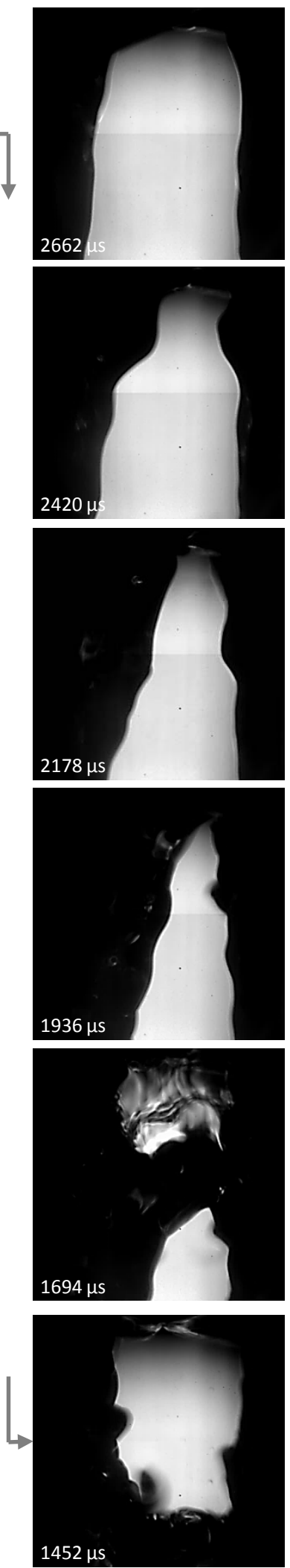

(b) $j_{G}=62.2 ; j_{L \times 3}=0.032 \mathrm{~m} / \mathrm{s}$
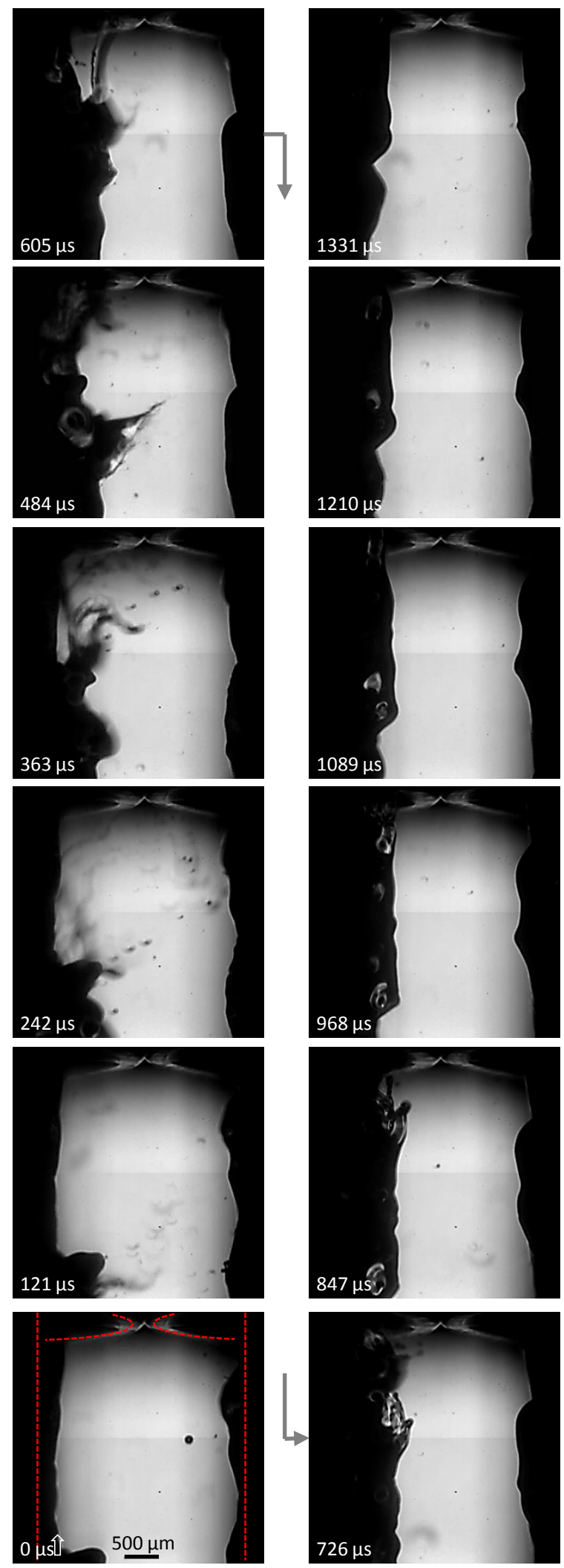
Fig. 21. Generation of liquid droplets at the top of the spacer structure.

(a) $j_{G}=31.8 ; j_{L \times 3}=0.032 \mathrm{~m} / \mathrm{s}$
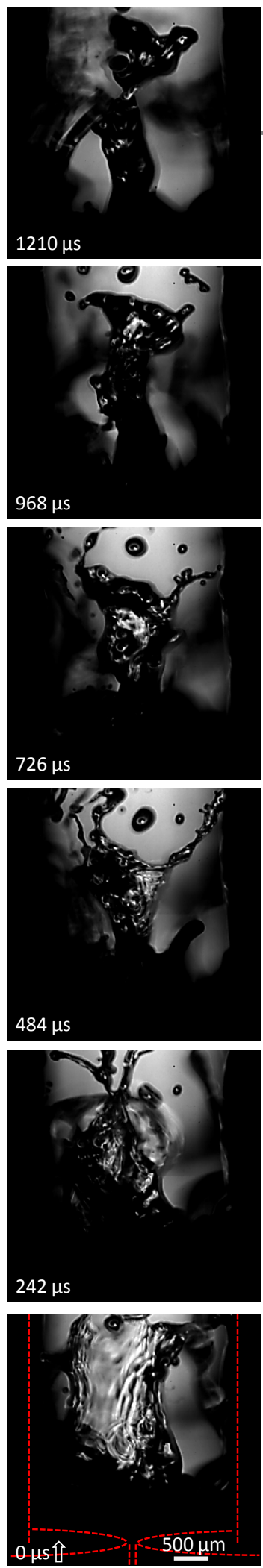
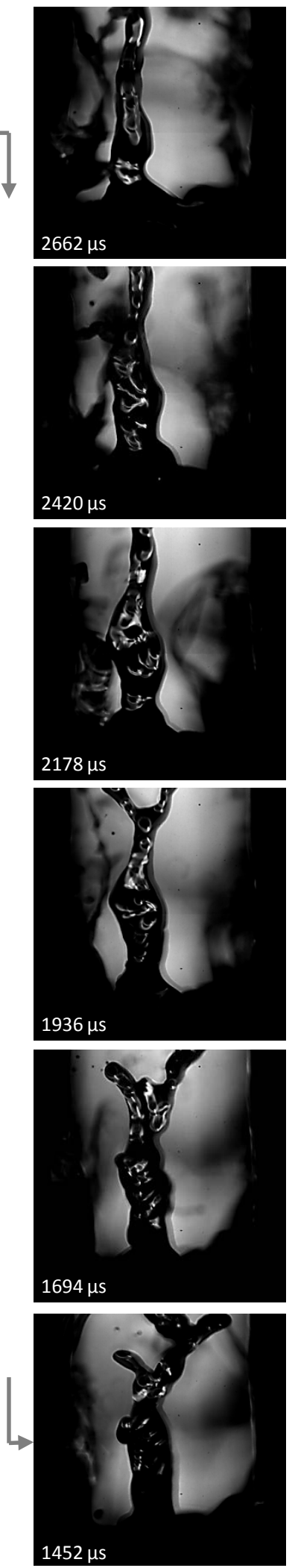

(b) $j_{G}=62.2 ; j_{L \times 3}=0.032 \mathrm{~m} / \mathrm{s}$
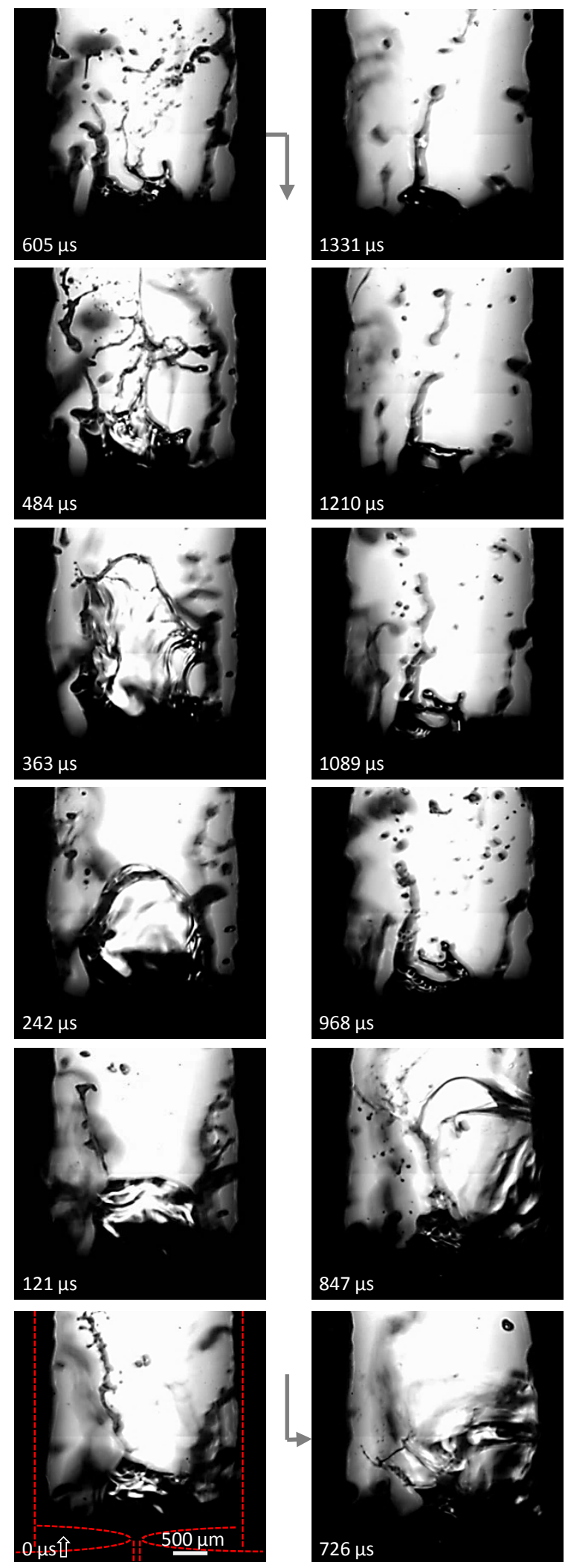
Fig. 22. Droplet behaviors at regions right up- and downstreams of the spacer. Image data are captured with $j_{G}=44.5 \mathrm{~m} / \mathrm{s}$ and $j_{L \times 3}=0.032 \mathrm{~m} / \mathrm{s}$.

(b)

(a)
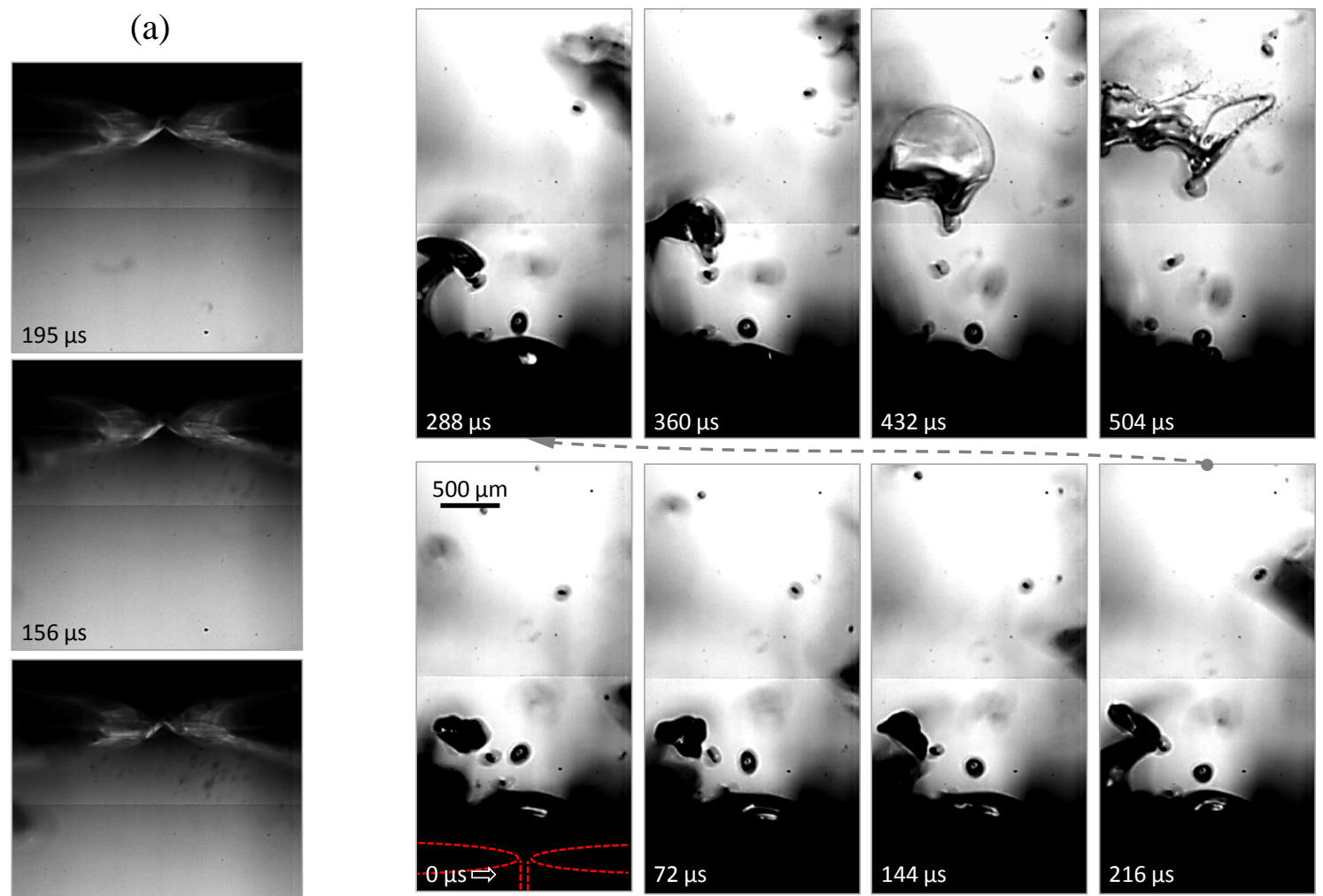

$117 \mu \mathrm{s}$
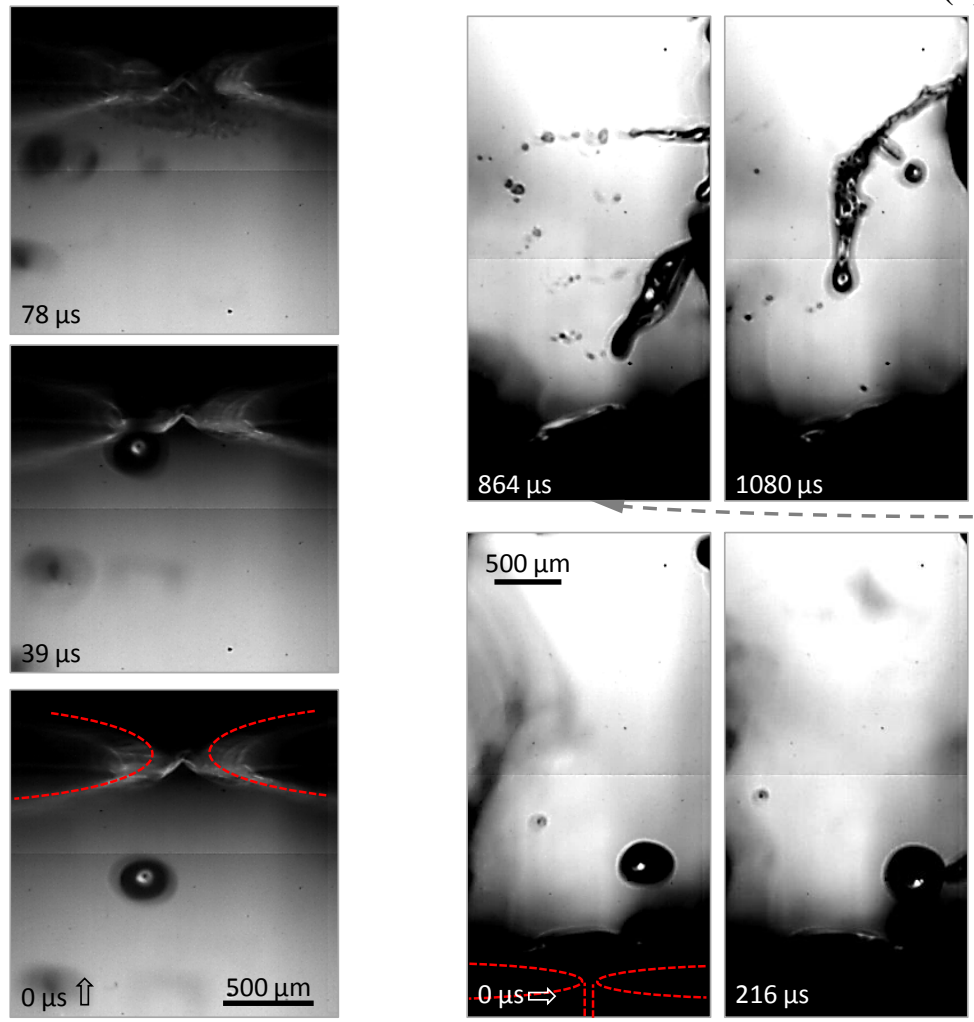

(c)
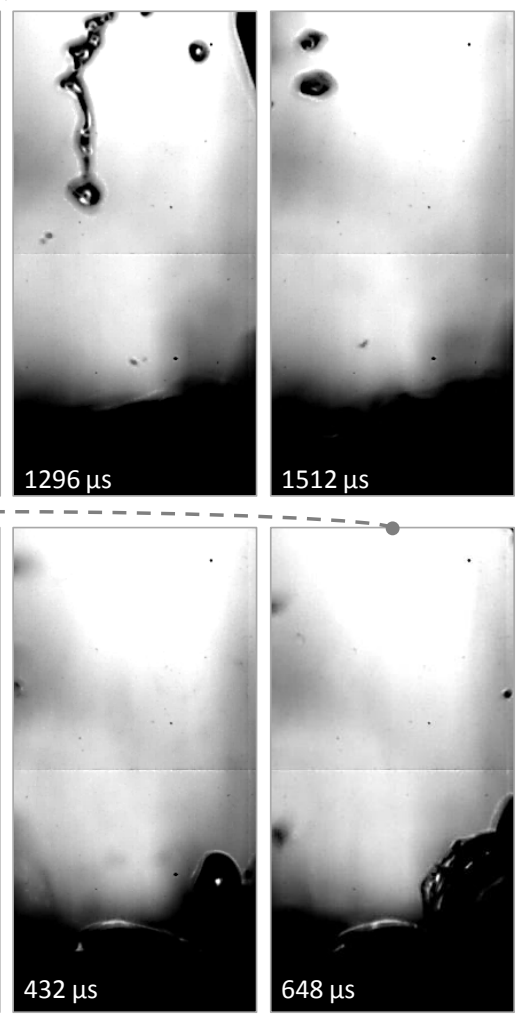